\title{
Article \\ Modulation of Volatile Thiol Release during Fermentation of Red Musts by Wine Yeast
}

\author{
Antonio G. Cordente ${ }^{1, *}$,, Christopher D. Curtin ${ }^{2}{ }^{\circledR}$, Mark Solomon ${ }^{1}{ }^{\circledR}$, Allie C. Kulcsar ${ }^{1}$, Flynn Watson ${ }^{1}$, \\ Lisa Pisaniello ${ }^{1}$, Simon A. Schmidt ${ }^{1}(\mathbb{D})$ and Damian Espinase Nandorfy ${ }^{1}$ \\ 1 The Australian Wine Research Institute, P.O. Box 197, Glen Osmond, SA 5064, Australia; \\ mark.solomon@awri.com.au (M.S.); allie.kulcsar@awri.com.au (A.C.K.); flynn.watson@awri.com.au (F.W.); \\ lisa.pisaniello@awri.com.au (L.P.); simon.schmidt@awri.com.au (S.A.S.); \\ damian.espinasenandorfy@awri.com.au (D.E.N.) \\ 2 Department of Food Science and Technology, Oregon State University, 100 Wiegand Hall, \\ Corvallis, OR 97331, USA; christopher.curtin@oregonstate.edu \\ * Correspondence: toni.garciacordente@awri.com.au; Tel.: +61-8-8313-6600; Fax: +61-8-8313-6601
}

check for updates

Citation: Cordente, A.G.; Curtin, C.D.; Solomon, M.; Kulcsar, A.C.; Watson, F.; Pisaniello, L.; Schmidt, S.A.; Espinase Nandorfy, D. Modulation of Volatile Thiol Release during Fermentation of Red Musts by Wine Yeast. Processes 2022, 10, 502. https://doi.org/10.3390/pr10030502

Academic Editor:

Antonella Costantini

Received: 8 February 2022

Accepted: 24 February 2022

Published: 2 March 2022

Publisher's Note: MDPI stays neutral with regard to jurisdictional claims in published maps and institutional affiliations.

Copyright: (C) 2022 by the authors. Licensee MDPI, Basel, Switzerland. This article is an open access article distributed under the terms and conditions of the Creative Commons Attribution (CC BY) license (https:// creativecommons.org/licenses/by/ $4.0 /)$.

\begin{abstract}
During the alcoholic fermentation of grape sugars, wine yeast produces a range of secondary metabolites that play a critical role in the aroma profile of wines. One of the most impactful yeastmodified compound families, particularly in white wines, are the 'fruity' polyfunctional thiols, which include 3-mercaptohexan-1-ol (3-MH) and 4-mercapto-4-methylpentan-2-one (4-MMP). While the formation and stylistic contribution of these thiols have been extensively researched in white wines, little is known about the conditions leading to their formation in red wines. In this study, we explored the ability of yeast strains to modulate the release of these aroma compounds during the fermentation of two red musts. In laboratory-scale Pinot Noir fermentations, the formation of 3-MH strongly correlated with yeast $\beta$-lyase activity, particularly with the presence of certain genotypes of the flavour-releasing gene $I R C 7$. Subsequent production of Grenache wine at the pilot scale, with detailed compositional and sensory analysis, was undertaken to confirm laboratory-scale observations. A commercial wine strain used for expressing 'fruity' thiols in Sauvignon Blanc was shown to produce wines that exhibited more intense red fruit aromas. These results reveal an opportunity for winemakers to shape red wine aroma and flavour by using yeasts that might typically be considered for white wine production.
\end{abstract}

Keywords: yeast; wine; sulphur; aroma; thiols

\section{Introduction}

The polyfunctional thiols 4-mercapto-4-methylpentan-2-one (4-MMP), 3-mercaptohexan1-ol (3-MH), and 3-mercaptohexyl acetate (3-MHA) impart 'passionfruit', 'grapefruit', 'guava', and 'box tree' aromas in white wines [1-3]. These compounds have very low perception thresholds, in the low nanogram-per-litre range, and are important contributors to the flavour of Sauvignon Blanc, Chardonnay and Scheurebe wines [4,5]. While the different precursors and pathways leading to the formation of these polyfunctional thiols, as well as their contributions to wine aroma and flavour, have been extensively studied in the context of wines made from white cultivars, little is known about their impact in red and rosé wines.

Polyfunctional thiols are present in red wines, although in lower concentrations than in white wines [6-8]. Capone, Ristic, Pardon and Jeffery [6] found concentrations of 3-MH and 3-MHA in commercial Pinot Noir and rosé wines comparable to those found in Chardonnay. A survey of 105 Australian commercial red wines also found concentrations of 3-MH well above its perception threshold $\left(60 \mathrm{ng} \mathrm{L}^{-1}\right)$ in a wide range of single variety red wines [9]. The highest concentrations of 3-MH were observed in Pinot Noir wines (around $500 \mathrm{ng} \mathrm{L}^{-1}$ on average), followed by Grenache. There is some evidence to suggest that polyfunctional 
thiols can contribute to the sensory profile of red wines. In red blends from the southeast of France, 'blackcurrant' aroma intensity was found to correlate with increasing concentrations of 4-MMP, while high concentrations of 3-MH acted as an enhancer for these 'blackcurrant' notes [7]. Both 3-MH and 3-MHA were also two of the components with the greatest capacity to differentiate the aroma of premium quality Spanish red wines [8]. In contrast, an aroma extract dilution analysis of two Oregon Pinot Noir wines did not find 4-MMP or 3-MH to be important aroma contributors [10].

The formation and fate of polyfunctional thiols in wine are mediated by several factors [11]. However, a prominent role is played by the Saccharomyces cerevisiae yeasts used to perform wine fermentation [12]. Choice of yeast strain modulates the concentration of 4-MMP, 3-MH, and 3-MHA in wine, as shown in S. Blanc and synthetic media fermentations [13-16]. On the other hand, little is known about how yeast strains modulate thiols in red wine fermentations. Recently, several yeast strains were used to ferment a must from the Italian red varietal Montepulciano d'Abruzzo, but none of the eight strains tested were found to release thiols in the finished wine [17].

It has been shown that 4-MMP and 3-MH exist in the grape berry as non-volatile, odourless precursors, mainly as conjugates of glutathione (GSH-4-MMP, GSH-3-MH) and cysteine (Cys-4-MMP, Cys-3-MH) [18,19], as well as breakdown intermediates cysteinylglycine and $\gamma$-glutamyl-cysteine $S$-conjugates (Cys-Gly-3-MH and $\gamma \mathrm{Glu}-\mathrm{Cys}-3-\mathrm{MH}$, respectively) [20-22]. No amino acid conjugates of 3-MHA have been identified, and evidence shows this compound is formed by acetylation of 3-MH by yeast alcohol acetyl transferase Atf1p [23], the enzyme responsible for the major part of volatile acetate ester production during fermentation [24]. Once the cysteinylated precursors are formed through degradation of their glutathionylated or dipeptide precursors, or assimilated from grape must, these are cleaved by yeast enzymes with cysteine- $S$-conjugate $\beta$-lyase activity (EC 4.4.1.13) to release the free thiols.

In $S$. cerevisiae, there are at least three genes encoding $\beta$-lyase activity: IRC7, STR3, and CYS3 [25-28]. Of these, Irc7p was found to be the key determinant of 4-MMP release from Cys-4-MMP and a significant contributor to 3-MH release from Cys-3-MH [16,25]. Interestingly, most strains of $S$. cerevisiae have a $38 \mathrm{bp}$ deletion in the $I R C 7$ coding sequence that results in a truncated protein of 340 amino acids (short Irc7p or Irc7p $\mathrm{p}$ ). The truncated form displays limited $\beta$-lyase activity when compared with the 400 amino acid full-length protein (long Irc7p or Irc $7 p^{L}$ ) $[16,25,29,30]$. Additionally, 4MMP release in synthetic and white wines was positively correlated with expression levels of $I R C 7^{L}$ for different industrial yeast strains $[17,31]$. Interestingly, the presence of the $I R C 7^{S}$ allele in wine strains has been linked to fitness and competitive advantages when compared to strains with the active $I R C 7^{L}$ allele, which might explain the higher prevalence of this inactive allele amongst wine populations [30].

We recently demonstrated that a yeast strain's capacity to release thiols could not be explained solely by IRC7 allele length [16]. Most wine strains with at least one copy of $I R C 7^{L}$ also harbour one or more deleterious single nucleotide polymorphisms (SNPs), which considerably reduces their $\beta$-lyase activity and capacity to release polyfunctional thiols. The most common of these SNPs results in the substitution of a threonine in position 185 to alanine (T185A), which was found to reduce the activity of the $I R C 7^{L}$ allele by half [16].

In this study, cysteine-S-conjugate $\beta$-lyase activity was evaluated for 39 S. cerevisiae strains previously shown to vary in thiol release capacity in laboratory media [16]. Eleven strains were selected based on their $\beta$-lyase activity and IRC7 genotype, and were used to ferment a Pinot Noir must. We show that yeast $\beta$-lyase activity, and the presence of particular alleles of $I R C 7$, is the main determinant that explains the release of the polyfunctional thiol 3-MH in red fermentations. Finally, sensory analyses of Grenache wines made with a subset of these yeast revealed a role of 3-MH and 3-MHA as potential enhancers of red fruit and cherry/confectionary aromas. Together, these results provide 
winemakers with additional options to modulate red wine aroma and flavour, through choice of suitable yeast strains depending on their desired style of wine.

\section{Materials and Methods}

\subsection{Chemicals}

Analytical reagents were purchased from Sigma-Aldrich (Castle Hill, NSW, Australia) unless otherwise indicated. The following compounds were synthesised in house as per the cited methods: 4-MMP and Cys-4MMP [13]; [ $\left.{ }^{2} \mathrm{H}_{10}\right] 4-\mathrm{MMP}, 3-\mathrm{MH},\left[{ }^{2} \mathrm{H}_{5}\right]-3-\mathrm{MHA}$, and 3MHA [32]; $\left[{ }^{2} \mathrm{H}_{10}\right] 3-\mathrm{MH}$ and Cys-3MH [33]; GSH-4-MMP and GSH-3MH (Fedrizzi, Pardon, Sefton, Elsey and Jeffery [19] and Grant-Preece, et al. [34], respectively); Cys-Gly-3MH [20].

\subsection{Microorganisms and Culture Conditions}

All yeast strains were obtained from the Australian Wine Research Institute (AWRI, Glen Osmond, SA, Australia) culture collection. Yeast cultures were maintained on solid YPD agar plates ( $2 \%$ glucose, $2 \%$ peptone, $1 \%$ yeast extract, and $2 \%$ agar). The integration of the $I R C 7^{S}, I R C 7^{L}$, and $I R C 7^{L} \mathrm{~T} 185 \mathrm{~A}$ alleles from different donor strains at the IRC7 chromosomal location of the haploid wine strain AWRI1631 is described in Cordente, Borneman, Bartel, Capone, Solomon, Roach and Curtin [16].

\subsection{Laboratory-Scale Fermentation of Pinot Noir}

Laboratory-scale fermentations were performed in triplicate in a Pinot Noir must with 11 strains with different thiol-releasing abilities (Table 1). Twenty kilograms of handpicked Pinot Noir grapes (2020 vintage) from the McLaren Vale wine region in South Australia (Australia) were crushed and destemmed, and $25 \mathrm{mg} \mathrm{L}^{-1} \mathrm{SO}_{2}$ and $3 \mathrm{~mL} / 100 \mathrm{~kg}$ of commercial pectolytic enzyme (Rohavin L, Redox, Adelaide, SA, Australia) was added. The must was left in contact with the skins for 2 days at $4{ }^{\circ} \mathrm{C}$, and then three press cycles ( 2 bar) were carried out. The basic physico-chemical composition of the Pinot Noir must was $177 \mathrm{mg} \mathrm{L}^{-1}$ yeast assimilable nitrogen, $233 \mathrm{~g} \mathrm{~L}^{-1}$ sugars, $1640 \mathrm{NTU}$ turbidity, and $\mathrm{pH}$ 3.44. Wines were fermented without the skins.

Table 1. Summary of $\beta$-lyase activity towards S-(2-Thiazolyl)-L-cysteine (STC) in cell-free protein extracts from 39 wine strains with different $I R C 7$ genotypes.

\begin{tabular}{|c|c|c|c|c|}
\hline $\begin{array}{l}\text { Main IRC7 } \\
\text { Genotype }^{\text {a }}\end{array}$ & Additional SNPs ${ }^{b}$ & $\begin{array}{l}\text { Strains } \\
\text { (n) }\end{array}$ & $\begin{array}{c}\beta \text {-Lyase Activity } \\
\left(\text { nmol } \text { min }^{-1} \mathrm{mg}_{\text {prot }}{ }^{-1}\right)^{c}\end{array}$ & $\begin{array}{l}\text { Strains Used for } \\
\text { Fermentations } d\end{array}$ \\
\hline$I R C 7^{S} / I R C 7^{S}$ & - & 15 & $1.99 \pm 0.31^{\mathrm{d}}$ & AWRI1833, AWRI2865 \\
\hline \multirow[t]{3}{*}{$\operatorname{IRC} 7^{S} / I R C 7^{L}$} & - & 5 & $6.42 \pm 1.3^{b}$ & AWRI2878 \\
\hline & $\operatorname{IRC} 7^{L} T 185 A$ & 5 & $2.96 \pm 1.28^{\mathrm{cd}}$ & AWRI2260 \\
\hline & IRC $7^{L}$ T185A P146R & 3 & $2.6 \pm 0.8^{\mathrm{cd}}$ & AWRI1776 \\
\hline \multirow[t]{5}{*}{$I R C 7^{L} / I R C 7^{L}$} & - & 5 & $10.6 \pm 2.35^{\mathrm{a}}$ & AWRI2914, AWRI1082 \\
\hline & $I R C 7^{L} / I R C 7^{L} T 185 A$ & 1 & $7.88^{a b}$ & AWRI2861 \\
\hline & IRC $7^{L} T 185 A / I R C 7^{L} T 185 A$ & 2 & $5.62 \pm 0.53 \mathrm{bc}$ & AWRI1688 \\
\hline & IRC $7^{L} T 185 A$ K43R/IRC $7^{L}$ T185A K43R & 2 & $3.94 \pm 1.06^{\mathrm{bcd}}$ & AWRI1493 \\
\hline & IRC $7^{L} T 185 A / I R C 7^{L} T 185 A$ G321D & 1 & $3.33^{\mathrm{bcd}}$ & AWRI778 \\
\hline
\end{tabular}

${ }^{\text {a }} I R C 7^{S}$ and $I R C 7^{L}$ depict the short and long alleles of $I R C 7$, respectively. ${ }^{b}$ Additional deleterious SNPs associated with $I R C 7^{L}$, as determined in Cordente et al. (2019). ${ }^{c}$ Means with the same superscript letter are not significantly different from each other (Tukey's test, $p<0.05$ ). ${ }^{d}$ Eleven strains were used in laboratory-scale fermentation in Pinot Noir; a subset of 6 strains (bold-face type) was used for pilot-scale winemaking in Grenache.

Yeast starter cultures were prepared by growing cells in YPD medium aerobically for $24 \mathrm{~h}$ to stationary phase at $28^{\circ} \mathrm{C}$. Then, $1 \times 10^{6}$ cells $\mathrm{mL}^{-1}$ were inoculated into $50 \%$ diluted Pinot Noir juice, which had been previously filtered through $0.22 \mu \mathrm{m}$ Stericup filters (Millipore), and grown for another $48 \mathrm{~h}$ at $22^{\circ} \mathrm{C}$. The acclimatised cells were inoculated into $220 \mathrm{~mL}$ of Pinot Noir must at a density of $1 \times 10^{6}$ cells $\mathrm{mL}^{-1}$. Fermentations were conducted at $17^{\circ} \mathrm{C}$ in $250 \mathrm{~mL}$ Schott bottles fitted with stir bars and stirred at $120 \mathrm{rpm}$ using a magnetic stirrer. The lids of the Schott bottles were fitted with gas detector tubes 
(Komyo, Kitagawa, Japan) to measure the release of $\mathrm{H}_{2} \mathrm{~S}$ during fermentation $\left(\mathrm{H}_{2} \mathrm{~S}\right.$ released). Fermentation progress was followed by $\mathrm{CO}_{2}$ weight loss, measured every $24 \mathrm{~h}$, which was completed ( $<2 \mathrm{~g} \mathrm{~L}^{-1}$ sugars) after 15 days. After fermentation, $\mathrm{SO}_{2}$ was added to a final concentration of $50 \mathrm{mg} \mathrm{L}^{-1}$ and ferments were cold-settled at $4{ }^{\circ} \mathrm{C}$ until sampled for different volatile and non-volatile compound analyses.

\subsection{Small Scale Winemaking of Grenache}

Small-lot wines were produced by the Wine Innovation Cluster (WIC) winemaking services, according to a standardised red winemaking protocol. Grenache grapes (2017 vintage) from a high-value McLaren Vale (South Australia, Australia) vineyard were handpicked with the following specifications (soluble solids $25.4^{\circ}$ Brix, $14.1^{\circ}$ Baume, $\mathrm{pH} 3.64$, titratable acidity pH $8.24 .2 \mathrm{~g} / \mathrm{L}$, and $249 \mathrm{mg} \mathrm{L}^{-1}$ yeast assimilable nitrogen, malic acid $1.88 \mathrm{~g} / \mathrm{L}$ ), and crushed with no $\mathrm{SO}_{2}$ added prior to fermentation. Crushed and destemmed grapes were partitioned into $50 \mathrm{~kg}$ lots and inoculated with the different strains in triplicate (Table 1) and fermented on skins at $20^{\circ} \mathrm{C}$. Wines were pressed at dryness and seeded for malolactic fermentation (MLF) with Oenococcus oeni VP41 (Lallemand), and incubated at $20{ }^{\circ} \mathrm{C}$ for a total of 98 days until MLF was completed in all the wines except for those made with strain AWRI2878. Wines were then sulphured and the $\mathrm{SO}_{2}$ concentration was adjusted to $45 \mathrm{mg} \mathrm{L}^{-1}$ of free $\mathrm{SO}_{2}$. Then, wines were cold-stabilised for approximately 2 months at $0{ }^{\circ} \mathrm{C}$ and filtered by cross-flow filtration before bottling. Screw-cap-sealed bottled wines $(375 \mathrm{~mL})$ were stored in the dark at a constant temperature of $15^{\circ} \mathrm{C}$ and analysed after 9 months. No oak was used in the winemaking.

\subsection{Assay of Cysteine-S-Conjugate $\beta$-Lyase Activity in Yeast Cell-Free Protein Extracts}

Strains were grown in YPD medium overnight at $28^{\circ} \mathrm{C}$, and a volume of $8 \mathrm{~mL}$ of the culture was centrifuged for $2 \mathrm{~min}$ at $4000 \mathrm{~g}$. Cells were washed twice with water, and the pellet was resuspended in $400 \mu \mathrm{L}$ of cold buffer containing HEPES $100 \mathrm{mM} \mathrm{pH} \mathrm{7.4,} 20 \mu \mathrm{M}$ pyridoxal-5'-phopshate (PLP), EDTA $200 \mu \mathrm{M}, 10 \%$ glycerol, and the protease inhibitors leupeptine $\left(2 \mu \mathrm{g} \mathrm{mL}^{-1}\right)$ and PMSF $(1 \mathrm{mM})$. Glass beads were added to the suspension, and cells were vortexed for $30 \mathrm{~s}$ and then allowed to rest for another $30 \mathrm{~s}$, for a total of $10 \mathrm{~min}$ (or 10 cycles) at $4{ }^{\circ} \mathrm{C}$. The suspension was centrifuged for $20 \mathrm{~min}$ at $16,000 \times g$ at $4{ }^{\circ} \mathrm{C}$, and the supernatant was used for enzyme assays. Protein concentrations were measured using the Bio-Rad protein assay (Cat. Number: 5000006), with bovine serum albumin as a standard.

Reactions were carried out at $30^{\circ} \mathrm{C}$ in a total volume of $200 \mu \mathrm{L}$ in 96 -well microplates (UV-Star ${ }^{\circledR}$ UV-Transparent Microplates, Greiner Bio-One, Kremsmünster, Austria), containing $100 \mathrm{mM}$ of HEPES buffer pH 7.4, $20 \mu \mathrm{M}$ PLP, and $25 \mu \mathrm{M}$ EDTA. A concentration of $2 \mathrm{mM}$ of L-cysteine or the L-cysteine conjugate S-(2-Thiazolyl)-L-cysteine (STC) (Santa Cruz Biotechnology, Dallas, TX, USA) was used. The reaction was started by adding $25 \mu \mathrm{g}$ of the yeast cell-free protein extracts. As a result of $\beta$-lyase activity, a sulphur-containing compound $\left(\mathrm{H}_{2} \mathrm{~S}\right.$ in the case of L-cysteine, and 2-mercaptothiazole for STC), as well as ammonia and pyruvate, were released.

For both $\beta$-lyase substrates, the release of pyruvate was assessed by HPLC (see below) after one hour of incubation. When using STC as the substrate, 2-mercaptothiazole was also quantified directly by measuring its absorbance at $310 \mathrm{~nm}$ every $5 \mathrm{~min}$ for $60 \mathrm{~min}$. The molar absorption coefficient $\left(\varepsilon=12,100 \mathrm{~L} \mathrm{~mol}^{-1} \mathrm{~cm}^{-1}\right)$ for 2-mercaptothiazole was calculated using different concentrations of the commercial substrate $(97 \%$, Alfa Aesar, Haverhill, MA, USA) dissolved in the reaction buffer. The assay using STC as the substrate was validated by quantifying the amount of both 2-mercaptothiazole and pyruvate released in the enzymatic reaction, using yeast cell-free protein extracts from 12 wine strains. A strong linear correlation was observed between pyruvate and 2-mercaptothiazole formation $(\mathrm{r}=0.97, p<0.0001)$, with equimolar concentrations of both compounds being produced $($ slope $=1.011)($ data not shown). 


\subsection{Analysis of Principal Non-Volatile Compounds by HPLC}

The concentrations of sugars, ethanol, glycerol, and organic acids (including pyruvate) were measured by HPLC using a Bio-Rad HPX-87H column [35]. Reference standards of the highest purity were obtained from Sigma-Aldrich.

\subsection{Analysis of Aroma Compounds}

Analysis of free thiols, 3-MH, 3-MHA, and 4-MMP, occurred once the Pinot Noir ferments achieved dryness, and were clarified by centrifugation $(2500 \times g$ for $5 \mathrm{~min})$ to remove yeast cells. Samples for free thiols were prepared using the method of Capone, Ristic, Pardon and Jeffery [6]. Briefly, an internal standard mix of $\mathrm{d}_{10}-3-\mathrm{MH}, \mathrm{d}_{5}-3-\mathrm{MHA}$, and $\mathrm{d}_{10}-4-\mathrm{MMP}$ in ethanol was added to $20 \mathrm{~mL}$ wine samples. The samples were then derivatised with an excess of 4,4'-dithiodipyridine (TCI, Asis Scientific, Adelaide, Australia), and then concentrated using SPE (Bond Elut C18, Agilent, Mulgrave, VIC, Australia). The resulting extract was dried at $29^{\circ} \mathrm{C}$ using a stream of nitrogen and finally reconstituted in $200 \mu \mathrm{L}$ of $10 \%$ ethanol in water.

Derivatised thiols were then analysed using an Exion UHPLC coupled to a 6500 QTrap+ (Sciex, Mulgrave, VIC, Australia) under the following conditions. A $10 \mu \mathrm{L}$ injection of the above extract was used for all compounds except for 3-MH, samples of which exceeded the linear range and required a reinjection of $5 \mu \mathrm{L}$. Calibration functions were prepared in a commercially available red wine and performed satisfactorily (Table S1). Compounds were separated using a Poroshell 120, EC-C18, $2.1 \times 100 \mathrm{~mm}, 2.7 \mu \mathrm{m}$ with a $2.1 \times 5 \mathrm{~mm}$ guard column of the same material (Agilent, Mulgrave, VIC, Australia) held at $45{ }^{\circ} \mathrm{C}$. The LC conditions were $0.5 \%$ acetic acid in water (solvent $\mathrm{A}$ ) and $0.5 \%$ acetic acid in acetonitrile (solvent $\mathrm{B}$ ), with a combined flow of $0.8 \mathrm{~mL} / \mathrm{min}$. The linear gradient for solvent $\mathrm{B}$ was $0 \mathrm{~min}, 17 \%$; $3 \mathrm{~min}, 35 \%$; $3.5 \mathrm{~min}, 100 \%$; and $4.5 \mathrm{~min}, 100 \%$; followed by 2.25 min of column re-equilibration with $17 \%$ B. To maximise sensitivity, mass transitions were monitored in 'scheduled MRM' with an acquisition window of $30 \mathrm{~s}$.

In a separate analysis, concentrations of bound thiols, namely, (R/S)-GSH-3-MH, $(R / S)$ Cys-Gly-3-MH, and (R/S)-Cys-3-MH, were prepared as per the method of Capone, Sefton, Hayasaka and Jeffery [18] and determined using an Exion UHPLC coupled to a 6500 Qtrap+ MS (Sciex, Mulgrave, VIC, Australia) system with the following modifications. The column used was a Poroshell 120, EC-C18, $2.1 \times 100 \mathrm{~mm}, 2.7 \mu \mathrm{m}$ with a $2.1 \times 5 \mathrm{~mm}$ guard column of the same material (Agilent, Mulgrave, VIC, Australia) and was held at $45^{\circ} \mathrm{C}$. The LC conditions were as follows: $0.5 \%$ aqueous formic acid (solvent $\mathrm{A}$ ) and $0.5 \%$ formic acid in acetonitrile (solvent $\mathrm{B}$ ), with a combined flow rate of $0.8 \mathrm{~mL} / \mathrm{min}$. The linear gradient for solvent $\mathrm{B}$ was as follows: $0 \mathrm{~min}, 7 \%$; $5.00 \mathrm{~min}, 7 \% ; 5.50 \mathrm{~min}, 100 \% ; 6.50 \mathrm{~min}, 100 \%$; followed by $2.50 \mathrm{~min}$ of column re-equilibration with $7 \%$ B. A $2 \mu \mathrm{L}$ injection volume was used for each sample. Additionally, GSH-4-MMP and Cys-4-MMP were incorporated into this analysis. Calibration functions were prepared in water and performed satisfactorily (Table S2).

Volatile sulphur compounds (VSCs) $\mathrm{H}_{2} \mathrm{~S}$, methanethiol (MeSH), dimethyl sulphide (DMS), diethyl sulphide, dimethyl disulphide, diethyl disulphide, ethanethiol (EtSH), carbon disulphide, methyl thioacetate (MeSAc), and ethyl thioacetate were determined using an Agilent 8355 sulphur chemiluminescence detector coupled to an Agilent 7890B gas chromatograph (Forest Hill, VIC, Australia). The analysis was carried out as described previously [36], with slight modifications. An Agilent DB Sulfur SCD column $(0.75 \mu \mathrm{m}$, $40 \mathrm{~m} \times 0.32 \mathrm{~mm}$ ) (Agilent, Mulgrave, VIC, Australia) with $1 \mathrm{~m}$ of retention gap $(0.53 \mathrm{~mm})$ was used with a flow rate of $2.7 \mathrm{~mL} / \mathrm{min}$.

$\mathrm{H}_{2} \mathrm{~S}$ released during fermentation was detected in the headspace using silver nitrate selective gas detector tubes (Komyo Kitagawa, Japan) [37].

For the Grenache wines, the above compounds together with those of fermentationderived compounds (esters, acids, and alcohols) and monoterpene and norisoprenoid compounds were quantified at the time of sensory evaluation using previously described methods [38]. 


\subsection{Sensory Evaluation}

The Grenache wines (six strains, triplicate fermentations) were evaluated after nine months in bottle using the quantitative descriptive analysis sensory method described in Heymann, et al. [39]. A panel of eleven assessors (seven females, four males) with an average age of 44 years $(\mathrm{SD}=11.3$ ) was convened from the pool of external AWRItrained descriptive analysis assessors to evaluate the wines. Assessors attended three two-hour training sessions, when all the wines from the study were progressively presented to determine appropriate descriptors by a consensus-based approach, for rating in the formal sessions. Sensory standards for aromas, basic tastes, and mouthfeel attributes were presented during training and practice sessions, and revisited prior to each formal evaluation day. The final list of attributes, definitions/synonyms, and reference standards are shown in Table S3. The intensity of each attribute listed in Table S4 was rated using an unstructured $15 \mathrm{~cm}$ line scale (numericised 0 to 10), with indented anchor points of 'low' and 'high' placed at 10\% and 90\%, respectively. Data were acquired using Fizz sensory software. Panel performance was assessed using Fizz software and R with the SensomineR() and FactomineR() packages.

For the evaluation conditions, three samples were presented to panellists in $30 \mathrm{~mL}$ aliquots in 3-digit-coded, covered, ISO standard wine glasses at $22{ }^{\circ} \mathrm{C}$, in isolated booths under daylight-type fluorescent lighting. Assessors evaluated 12 samples per two-hour session. The assessors had a $60 \mathrm{~s}$ rest between samples and were encouraged to rinse with water, and a minimum ten-minute rest outside of the sensory booths between sets of three. Formal evaluation was completed in three sessions on separate days, with each fermentation replicate assessed in duplicate. New bottles were used for each of the presentation days. Randomised presentation order was followed using a Williams Latin square design.

\subsection{Statistical Analysis}

Minitab 19 statistical software (Minitab Inc., Pennsylvania, USA) was used for statistical analysis. The chemical data were analysed by one-way ANOVA, using Tukey's honestly significant different test (alpha $=0.05)$, and $P$ values were determined by a two-tailed Student's $t$ test. GraphPad 8 for Windows (GraphPad Software, San Diego, USA) was also used for regression (statistical) analysis and graphing. For the sensory data, a nested ANOVA was conducted for the effects of treatment, judge, judge by treatment, ferment replicate nested into treatment, judge by ferment replicate nested into treatment, and presentation replicate nested into treatment and ferment replicate, treating judge as a random effect. A post-hoc Tukey test was calculated at a 95\% confidence level for attributes showing statistical evidence to have differed across strain effect using the judge by treatment error term. To explore and model the relationships between wine composition and sensory data of the treatment fermentation replicates, Partial Least Squares Regression (PLS-R) was conducted similarly to that described in Day, et al. [40]. Briefly, chemical variables $\left(x^{\prime} \mathrm{s}\right)$ and sensory responses ( $y$ 's) were standardised, full cross-validation was performed, and the NIPALS algorithm was used with 30,000 iterations calculated. To avoid overfitting, PLS-R models were constructed and interpreted considering both the optimal number of factors and inspection of the residual validation variance using The Unscrambler X (CAMO Software, Oslo, Norway).

\section{Results}

\subsection{Enzymatic Assay for Cysteine-S-Conjugate $\beta$-Lyase Activity in Yeast Cell-Free} Protein Extracts

PCR analysis of yeast for the presence of the long and active allele of IRC7 $\left(I R C 7^{L}\right)$, encoding the major cysteine-S-conjugate $\beta$-lyase, has been previously used to classify strains for their potential ability to release polyfunctional thiols from cysteinylated precursors $[25,29,31]$. However, analysis of the genomic sequence of 179 wine yeasts showed that around $80 \%$ of strains with at least one copy of $I R C 7^{L}$ have one or more deleterious SNPs associated with this allele [16]. Therefore, the presence of the $I R C 7^{L}$ allele alone, as 
determined by the PCR assay, does not sufficiently indicate the thiol-releasing potential of a wine yeast strain. This fact prompted us to develop a spectrophotometric method to assess yeast $\beta$-lyase activity in cell-free protein extracts. The method uses $S$-(2-Thiazolyl)-Lcysteine (STC) as the substrate, which has the advantage of providing direct quantification of 2-mercaptothiazole, released as a result of $\beta$-lyase activity, without the need for any coupling enzymatic reactions or derivatisation of the reaction products [41]. This assay was first validated in the haploid AWRI1631 background, which harbours the inactive $I R C 7^{S}$ allele. The wild-type locus was replaced by either the fully active $I R C 7^{L}$ or the partially active $I R C 7^{L}$ T185A allele [16]. Comparison of the results obtained with the $I R C 7^{L}$ and $I R C 7^{S}$ alleles showed that around $90 \%$ of the total $\beta$-lyase activity observed was due to the presence of an active copy of Irc $7 \mathrm{p}^{\mathrm{L}}$, while the T185A mutation reduced the activity of the $I R C 7^{L}$ allele by $64 \%$ (Figure 1). The specific activity of $\operatorname{Irc} 7 \mathrm{p}^{\mathrm{L}}$ towards its physiological substrate L-cysteine was approximately 7 times lower than that for STC.

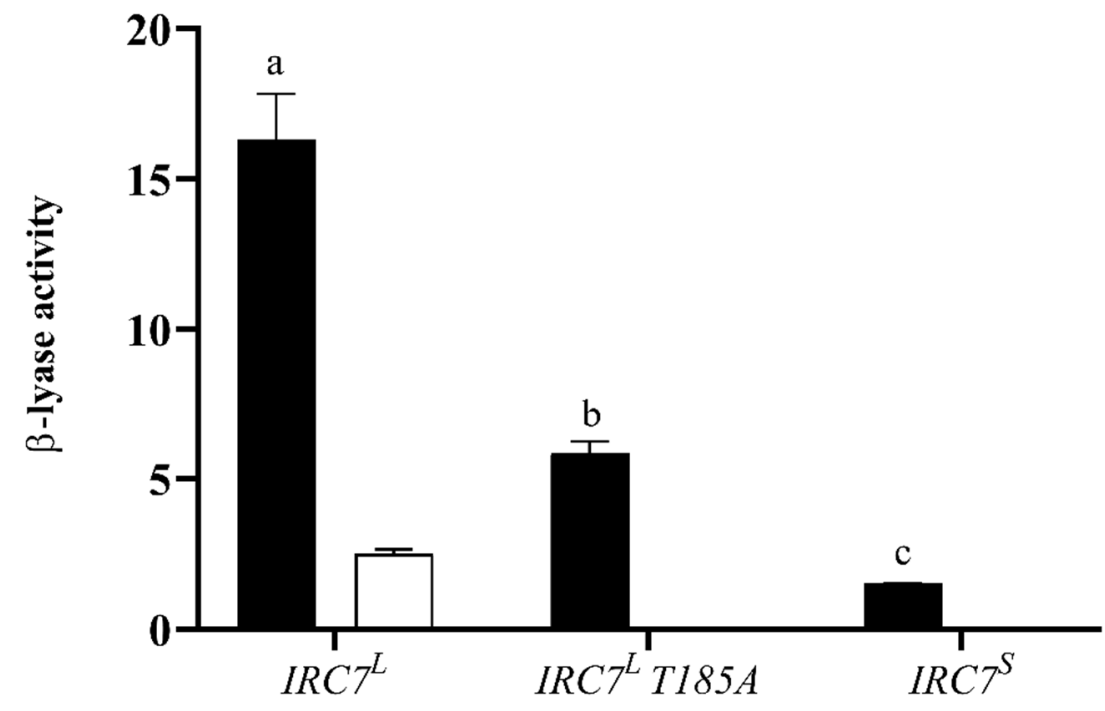

\section{IRC7 genotype}

Figure 1. Enzymatic $\beta$-lyase activity towards S-(2-Thiazolyl)-L-cysteine (STC) (black) and L-cysteine (white) in cell-free protein extracts from the haploid strain AWRI1631 with chromosomal integration of different $I R C 7$ genotypes. Each result is the mean and standard deviation of three independent replicates, and expressed as nmol $\mathrm{min}^{-1} \mathrm{mg}_{\text {protein }}{ }^{-1}$. For STC, the release of the thiol compound 2-mercaptothiazole was measured spectrophotometrically; for L-cysteine, the release of pyruvate was assessed by HPLC. No detectable activity was observed for the $I R C 7^{L} \mathrm{~T} 185 \mathrm{~A}$ and $I R C 7^{S}$ alleles using L-cysteine. Means with the same superscript letter are not significantly different from each other (Tukey's test, $p<0.05$ ).

The $\beta$-lyase assay with STC as the substrate was used to assess a set of 39 wine strains (summarised in Table S5), which were previously shown to exhibit different IRC7 genotypes and the capacity to release 3-MH from the cysteinylated precursor in laboratory media [16]. A ninefold variation in enzymatic activity was observed between the different wine strains. Strains homozygous $\left(I R C 7^{L} / I R C 7^{L}\right)$ or heterozygous $\left(I R C 7^{S} / I R C 7^{L}\right)$ for the long allele, and with no deleterious SNPs associated with this allele, had average enzymatic

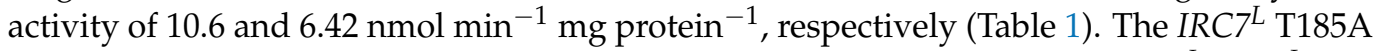
allele approximately halved the $\beta$-lyase activity of strains with the main $I R C 7^{L} / I R C 7^{L}$ and $I R C 7^{S} / I R C 7^{L}$ genotypes. Additional mutations associated with the $I R C 7^{L} \mathrm{~T} 185 \mathrm{~A}$ allele reduced $\beta$-lyase activity to levels similar to those of the inactive $I R C 7^{S} / I R C 7^{S}$ genotype (Table 1). 


\subsection{Laboratory-Scale Fermentations in Pinot Noir Must}

A set of 11 wine yeast strains was selected (Table 1), representative of each of the most common IRC7 genotypes, to test whether yeast $\beta$-lyase activity would affect polyfunctional thiol concentrations in Pinot Noir wines.

Fermentation using the subset of yeasts resulted in wines with 3-MH concentrations that varied by 18 -fold from 159 to $2911 \mathrm{ng} \mathrm{L}^{-1}$, and 3-MHA concentrations that varied by 43-fold from 6.3 to $271 \mathrm{ng} \mathrm{L}^{-1}$ (Figure 2). As expected, the concentrations of 3-MH and the acetate ester 3-MHA were highly correlated $(r=0.95, p<0.0001)$ (data not shown). No $4-\mathrm{MMP}$ could be detected in any Pinot Noir wines. A strong correlation $(\mathrm{r}=0.94, p<0.0001)$ was observed between the sum of thiol concentrations (3-MH and 3-MHA) in the wines and the $\beta$-lyase activity of the strains (Figure 3).

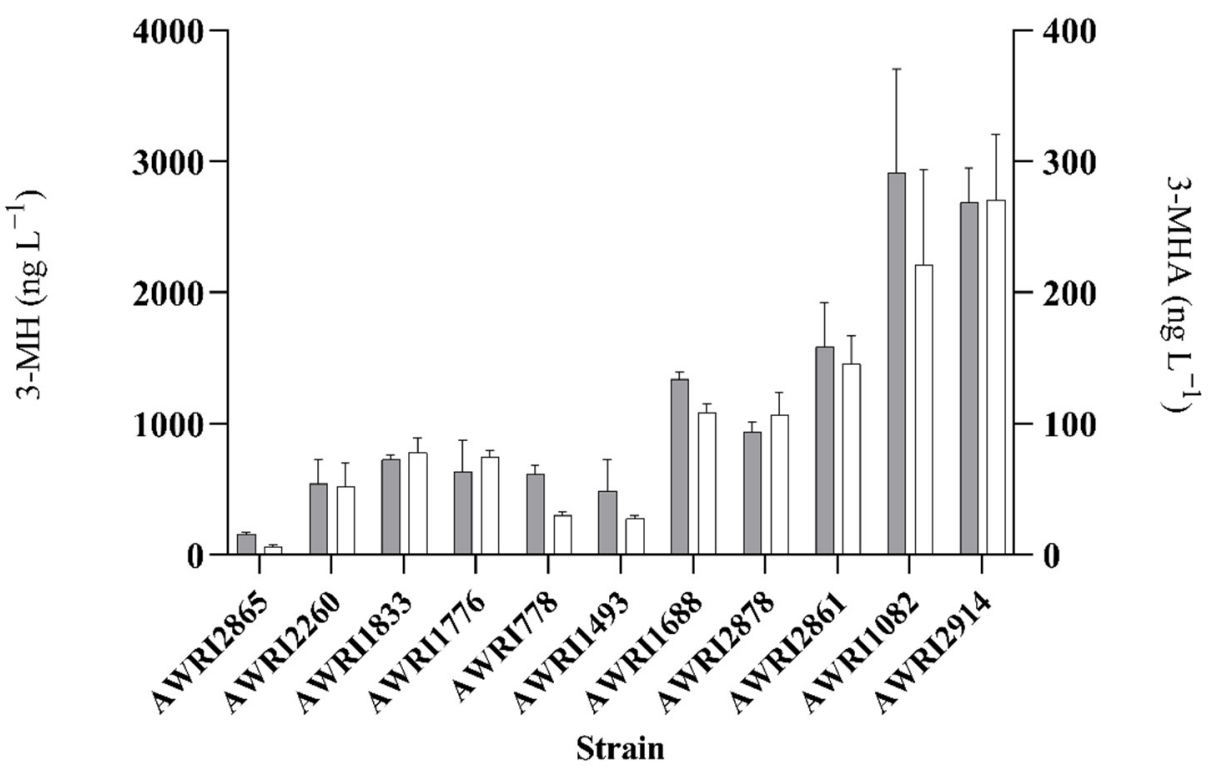

Figure 2. Concentration of 3-MH (grey) and 3-MHA (white) in wine after fermentation of a Pinot Noir must $(220 \mathrm{~mL})$ by 11 yeast strains with different IRC7 genotypes. Each bar (in $\mathrm{ng} \mathrm{L}^{-1}$ ) represents the mean and standard deviation of three independent fermentation replicates. In the graph, the 11 yeast strains are shown in ascending order according to their specific $\beta$-lyase activity.

The fate of different non-volatile precursors of 3-MH (Cys-3-MH, GSH-3-MH, and Cys-Gly-3-MH) was also determined. In the Pinot Noir must, the most abundant precursor was GSH-3-MH, which accounted for $81 \%$ of the total potential source for 3-MH, followed by Cys-3-MH (16.5\%) and Cys-Gly-3-MH (2.5\%) (Table 2). On the other hand, both 4-MMP precursors analysed (GSH-4-MMP and Cys-4-MMP) were below their quantification limits (0.87 and $0.57 \mu \mathrm{g} \mathrm{L}^{-1}$, respectively). At the end of alcoholic fermentation, there was a marked variability in the concentrations of GSH-3-MH in the wines fermented with different strains (Table 2). While most of the initial GSH-3-MH could still be found in the wines fermented with the lowest 3-MH producer (AWRI2865), the four highest thiolreleasing strains (>1000 $\mathrm{ng} \mathrm{\textrm {L } ^ { - 1 }}$ of $\left.3-\mathrm{MH}\right)$ had consumed more than $90 \%$ of the initial GSH-3-MH present in the juice. A weak correlation $(\mathrm{r}=0.58, p=0.058)$ was observed between GSH-3-MH consumption and thiol formation by the different yeast treatments (Figure 4); however, when only the wines fermented with the seven strains with a low and moderate thiol-releasing ability $\left(<1000 \mathrm{ng} \mathrm{L}^{-1} 3-\mathrm{MH}\right)$ were considered, a stronger linear relationship $(\mathrm{r}=0.85, p=0.015)$ was found (Figure 4$)$. Regarding the other two potential precursors of 3-MH, Cys-3-MH and Cys-Gly-3-MH, no significant correlation was observed between their consumption and thiol formation (Table S6). 


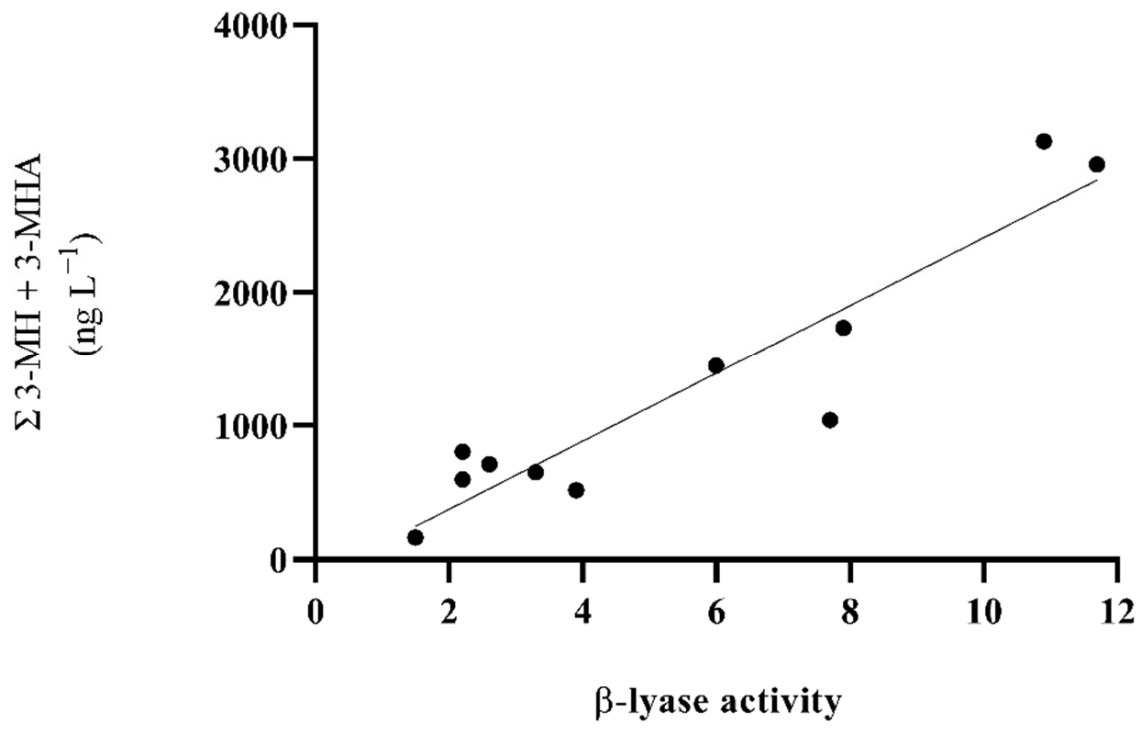

Figure 3. Correlation between yeast $\beta$-lyase activity and thiol ( $\Sigma$ 3-MH $+3-\mathrm{MHA})$ concentrations (ng L ${ }^{-1}$ ) after fermentation of a Pinot Noir must $(220 \mathrm{~mL})$ by 11 wine strains with different IRC7 genotypes. $\beta$-lyase activity (in $\mathrm{nmol} \mathrm{\textrm {min } ^ { - 1 } \mathrm { mg } \text { protein }}{ }^{-1}$ ) was calculated using cell-free protein extracts from each of the wine strains and STC as the substrate. The correlation coefficient (r) was found to be $0.94(p<0.0001)$.

Table 2. Concentrations of 3-MH precursors in the Pinot Noir must and in finished wines fermented with 11 strains with different $I R C 7$ genotypes.

\begin{tabular}{|c|c|c|c|c|c|}
\hline & \multicolumn{3}{|c|}{ Precursor Concentration $\left(\mu \mathrm{g} \mathrm{L}^{-1}\right)$} & \multirow{2}{*}{$\begin{array}{l}\% \text { Precursor } \\
\text { Consumption }\end{array}$} & \multirow{2}{*}{$\begin{array}{c}\text { \% Maximum Molar } \\
\text { Conversion a }^{\text {a }}\end{array}$} \\
\hline & $(R / S)-G S H-3-M H$ & $(R / S)-C y s-G l y-3-M H$ & $(R / S)-C y s-3-M H$ & & \\
\hline $\begin{array}{l}\text { Grape must } \\
\text { Wines }\end{array}$ & 1176 & 24.9 & 129.7 & & \\
\hline AWRI1082 & $13.2 \pm 0.8$ & $28.1 \pm 2.7$ & $0.6 \pm 0.1$ & 96.2 & 0.66 \\
\hline AWRI1493 & $627 \pm 26.2$ & $32.1 \pm 4.2$ & $58.9 \pm 0.9$ & 46.1 & 0.10 \\
\hline AWRI1688 & $33.9 \pm 4.6$ & $5.2 \pm 0.6$ & $1.3 \pm 0.2$ & 97.0 & 0.30 \\
\hline AWRI1776 & $220 \pm 9.0$ & $19.7 \pm 2.1$ & $1.1 \pm 0.2$ & 82.7 & 0.14 \\
\hline AWRI1833 & $288 \pm 1.1$ & $12.8 \pm 0.7$ & $1.3 \pm 0.1$ & 78.7 & 0.17 \\
\hline AWRI2260 & nd & $3.7 \pm 0.2$ & $0.9 \pm 0.1$ & 99.5 & 0.13 \\
\hline AWRI2861 & $18.5 \pm 0.1$ & $7.7 \pm 0.9$ & $2.5 \pm 0.3$ & 97.6 & 0.36 \\
\hline AWRI2865 & $1085 \pm 23$ & $59.7 \pm 1.6$ & $120.1 \pm 8$ & 4.0 & 0.03 \\
\hline AWRI2878 & nd & nd & $3.7 \pm 0.4$ & 99.5 & 0.22 \\
\hline AWRI2914 & $9.4 \pm 0.8$ & $4.4 \pm 0.6$ & $58.0 \pm 5.8$ & 91.5 & 0.62 \\
\hline AWRI778 & $531 \pm 71$ & $12.1 \pm 1.5$ & $127.3 \pm 13$ & 46.0 & 0.14 \\
\hline
\end{tabular}

Results are expressed as the mean and standard deviation of three independent replicates. ${ }^{a}$ Maximum molar conversion of the three precursors into the free thiols $(\Sigma 3-\mathrm{MH}+3-\mathrm{MHA})$.

The formation of negative VSCs was also analysed in the Pinot Noir wines as Irc7p shows cysteine desulphydrase activity, and as such can release $\mathrm{H}_{2} \mathrm{~S}$ from the amino acid Lcysteine [42]. Even though yeast differed considerably in their ability to release the different VSCs quantified (Table 3), no correlation was observed between yeast $\beta$-lyase activity and $\mathrm{H}_{2} \mathrm{~S}$ concentrations in the final wines $(\mathrm{r}=-0.19, p=0.60)$, nor with the amount $\mathrm{H}_{2} \mathrm{~S}$ produced during fermentation $\left(\mathrm{H}_{2} \mathrm{~S}\right.$ released $)(\mathrm{r}=0.50, p=0.114)$ (Table S7). Interestingly, a weak correlation was observed between the levels of 3-MH in wine and the amount of $\mathrm{H}_{2} \mathrm{~S}$ released during fermentation $(r=0.66, p=0.029)$ (Figure $\mathrm{S} 1$ ). 


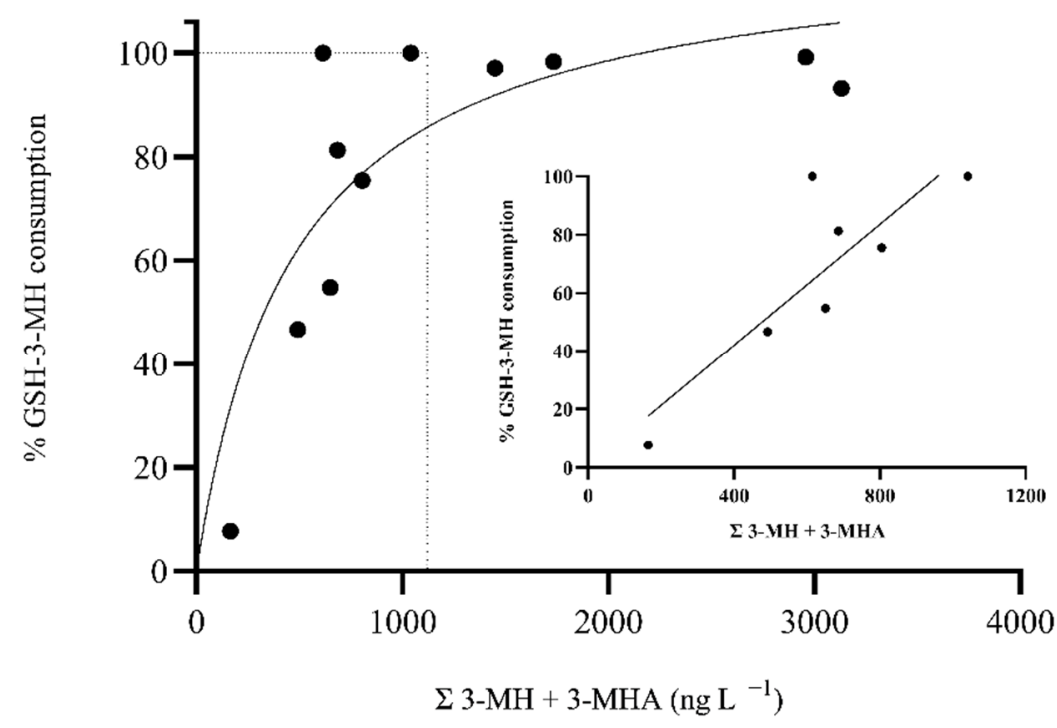

Figure 4. Relationship between the consumption of GSH-3-MH (percentage related to the initial concentration in the must) and free thiol production ( $\Sigma 3-\mathrm{MH}$ and 3-MHA) after fermentation of a Pinot Noir must by 11 wine strains with different $I R C 7$ genotypes. The solid line represents the non-linear least squares fitting curve between variables $(\mathrm{r}=0.84)$. The area under the dotted lines is zoomed in to highlight the linear relationship between these two variables for a subset of 7 strains with low and moderate thiol-releasing abilities $(r=0.85, p=0.015)$.

Table 3. Effect of different yeast strains in VSC formation after Pinot Noir fermentation.

\begin{tabular}{|c|c|c|c|c|c|}
\hline \multirow{2}{*}{ Strain } & \multicolumn{4}{|c|}{$\operatorname{VSC}\left(\mu \mathrm{g} \mathrm{L}^{-1}\right)$} & \multirow{2}{*}{$\mathrm{H}_{2} \mathrm{~S}$ Released $(\mu \mathrm{g})^{a}$} \\
\hline & $\mathrm{H}_{2} \mathrm{~S}$ & $\mathrm{MeSH}$ & $\mathrm{EtSH}$ & MeSAc & \\
\hline AWRI1082 & $2.2 \pm 0.2$ & 0 & 0 & $5.5 \pm 0.8$ & $112 \pm 12$ \\
\hline AWRI1493 & $1.3 \pm 0.1$ & $0.9 \pm 0.1$ & 0 & $7.9 \pm 2.3$ & $66 \pm 3.5$ \\
\hline AWRI1688 & $1.7 \pm 0.2$ & $1.0 \pm 0.1$ & 0 & $9.2 \pm 2.2$ & $124 \pm 2.1$ \\
\hline AWRI1776 & $2.6 \pm 0.4$ & 0 & 0 & $17.4 \pm 2.6$ & $60 \pm 1.4$ \\
\hline AWRI1833 & $4.0 \pm 0.4$ & $0.8 \pm 0.1$ & $1.2 \pm 0.1$ & $6.0 \pm 1.1$ & $67 \pm 2.9$ \\
\hline AWRI2260 & $2.4 \pm 0.1$ & $0.9 \pm 0.1$ & 0 & $17.4 \pm 2.4$ & $55 \pm 0.8$ \\
\hline AWRI2861 & $2.0 \pm 0.3$ & $1.1 \pm 0.2$ & 0 & $19.9 \pm 16.8$ & $57 \pm 6.6$ \\
\hline AWRI2865 & $1.9 \pm 0.5$ & 0 & 0 & 0 & $6.7 \pm 0.4$ \\
\hline AWRI2878 & $0.7 \pm 0.6$ & 0 & 0 & 0 & 0 \\
\hline AWRI2914 & $2.3 \pm 0.5$ & $1.0 \pm 0.3$ & 0 & $17.9 \pm 4.5$ & $163 \pm 1.6$ \\
\hline AWRI778 & $0.9 \pm 0.8$ & 0 & 0 & $7.8 \pm 0.9$ & $113 \pm 3.5$ \\
\hline
\end{tabular}

Results are expressed as the mean and standard deviation of three independent replicates. ${ }^{\text {a }} \mathrm{H}_{2} \mathrm{~S}$ released during fermentation was measured using silver nitrate selective gas detector tubes.

\section{Pilot-Scale Winemaking with Grenache}

Six strains with different thiol-releasing abilities, as shown previously in both enzymatic assays and Pinot Noir ferments, were chosen for a pilot-scale winemaking trial using Grenache grapes. Four strains (AWRI1833, 778, 2260, and 1776) were categorised as low thiol potential, one as moderate (AWRI2878), and one (AWRI2914) as having a strong thiol-releasing phenotype.

The different strains fermented at a similar rate, and ferments were dry after 9 days at $20^{\circ} \mathrm{C}$, except for AWRI1776, which took slightly longer (13 days) (data not shown). Malolactic fermentation was completed after approximately 3 months in all wines, except those made with AWRI2878. Analysis of volatile aroma compounds was undertaken nine months after the wines had been bottled, contemporaneously with sensory evaluation. The wines made with different yeast strains exhibited diverse volatile aroma compound profiles 
(summarised in Table S8), in addition to their varied capacity to release 3-MH and 3-MHA (Figure 5).

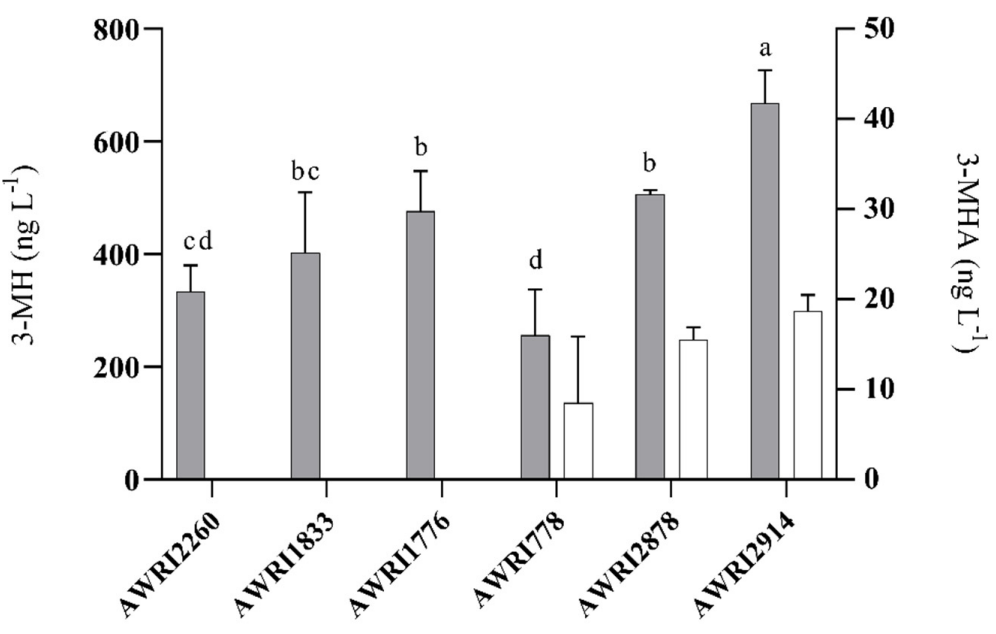

Strain

Figure 5. Concentration of 3-MH (grey) and 3-MHA (white) in Grenache wines fermented with 6 yeast strains with different $I R C 7$ genotypes, after 9 months in bottle. Each bar (in $\mathrm{ng} \mathrm{L}^{-1}$ ) represents the mean and standard deviation of three independent fermentation replicates. The 6 yeast strains are shown in ascending order according to their specific $\beta$-lyase activity. Means with the same superscript letter are not significantly different from each other (Tukey's test, $p<0.05$ ).

Wines made with AWRI2914 exhibited the highest 3-MH and 3-MHA concentrations (662 and $18.9 \mathrm{ng} \mathrm{L}^{-1}$, respectively), consistent with its high $\beta$-lyase activity. Wines made with the four low $\beta$-lyase activity strains averaged $363 \mathrm{ng} \mathrm{L}^{-1}$ of 3-MH, with only one of these strains, AWRI778, producing quantifiable amounts of 3-MHA (8.5 ng L $\left.{ }^{-1}\right)$. AWRI2878, the moderate $\beta$-lyase activity strain, produced intermediate levels of 3-MH and 3-MHA (508 and $15.5 \mathrm{ng} \mathrm{L}^{-1}$, respectively). As in the Pinot Noir experiments, no detectable levels of 4-MMP could be found in any of the Grenache wines.

\section{Quantitative Sensory Descriptive Analysis of the Grenache Wines}

The wines from the different yeast strains were evaluated by sensory descriptive analysis to determine if strain differences influenced Grenache sensory properties. From the ANOVA F-values shown in Table S9, very strong statistical evidence $(p<0.009)$ was found that attributes red colour intensity, brown tinge, red fruit aroma, cherry/confectionary aroma, tinned vegetable, and stewed apple/port-like flavour were rated differently across yeast strains. Weaker evidence supported $(p<0.05)$ yeast strain effects influencing drain aroma.

The largest relative effect size was for the appearance attributes red colour intensity and brown tinge, rated lowest and highest, respectively, for wines made with AWRI1776, which took longer to complete alcoholic fermentation. These wines were also rated highly in stewed apple/port-like flavour, tinned vegetable, and drain aroma, indicating the presence of some 'reductive' off-odours (Table S4). The fruity aroma attributes red fruit and cherry/confectionary were rated highest for strains AWRI2914 and AWRI1833. AWRI778 and AWRI2878 were intermediate, and the slightly 'reductive' wines from AWRI2260 and AWRI1776 were rated lowest (Table S4).

\section{Linking Chemical Composition to Sensory Properties}

To assess the relationships between the Grenache wine chemical composition and the sensory attribute ratings, a PLS-R model was developed using the mean data for each of the fermentation replicates. A two-factor model was considered optimal, with $48 \%$ of the variance in the sensory data explained (Figure 6). The importance of compounds to the whole model, and to particular attributes, was determined by considering R-square 
values (predicted vs measured), each compound's statistical significance as indicated by the uncertainty test, and the weighted regression coefficient values $\left(\beta_{\mathrm{w}}\right)$.

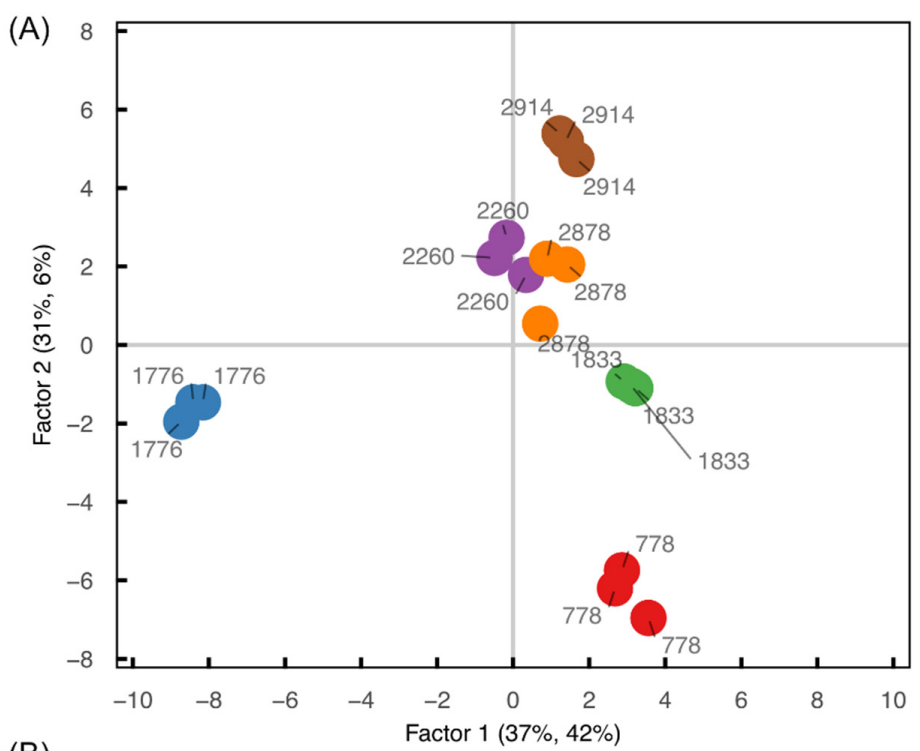

(B)

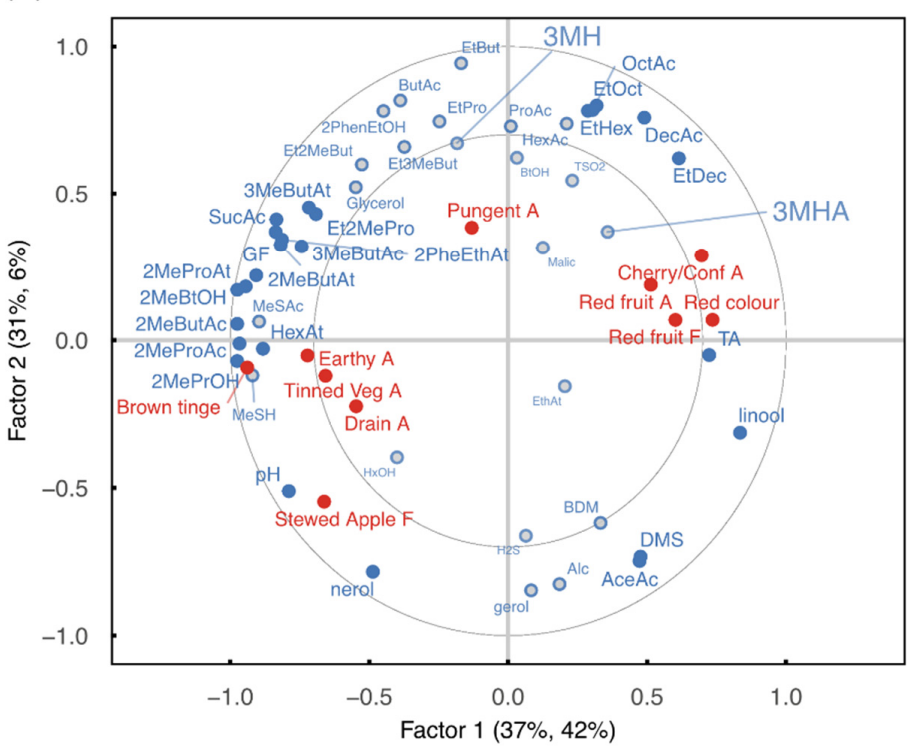

Figure 6. Factor 1 and 2 for the scores (A) and loadings (B) plots from partial least squares (PLS) regression models for Grenache wines after 9 months generated using important sensory attributes $(Y$ variables, red) and compositional compounds ( $X$ variables, blue) for each fermentation replicate of the winemaking treatments (yeast strains). Compounds significant to each PLS model are indicated by filled blue circles, and compounds with a lesser contribution to the model are shown as open circles and with smaller text. The proportion of the $X$ variance explained by the two factors is denoted by the first value in parentheses, the proportion of $Y$ variance by the second value. Chemical composition and labels are summarised in Table S8. A, aroma attributes; F, flavour attributes. Both thiols 3-MH and 3-MHA are highlighted in the figure with larger text.

The appearance terms were relatively well modelled (red colour intensity $\mathrm{R}^{2}$ calibration $=0.55$, validation $=0.45$; and brown tinge $R^{2}$ calibration $=0.89, R^{2}$ validation $\left.=0.84\right)$, and were associated with $\mathrm{pH}$ differences between wines. Of the aroma and palate attributes modelled, only cherry/confectionary aroma $\left(\mathrm{R}^{2}\right.$ calibration $=0.57, \mathrm{R}^{2}$ validation $\left.=0.44\right)$ and stewed apple/port-like flavour $\left(\mathrm{R}^{2}\right.$ calibration $=0.74, \mathrm{R}^{2}$ validation $\left.=0.59\right)$ were well modelled. For cherry/confectionary aroma, 3-MH and 3-MHA had relatively high positive regression coefficients of $\beta_{\mathrm{w}}=0.026$ and $\beta_{\mathrm{w}}=0.031$, respectively (Figure $7 \mathrm{a}$ ). Other 
volatile compounds with positive regression coefficients significantly associated with cherry/confectionary aroma were ethyl hexanoate, ethyl octanoate, octanoic acid, ethyl decanoate, decanoic acid, linalool, and DMS. For the attribute stewed apple/port-like flavour, succinic acid, residual sugar, methyl-2-propanol, acetic acid, ethyl-2-methylpropanoate, 3-methylbutanol, ethyl-2-methylbutanoate, 3-methylbutyl acetate, 2-methyl butanoic acid, hexyl acetate, 2-phenylethyl acetate, $\mathrm{MeSH}$, and MeSAc were significant and positively associated (Figure 7c). Conversely, 3-MH and 3-MHA had strongly negative regression coefficients but were not significant according to the uncertainty test. For red fruit aroma (Figure $7 \mathrm{~b}$ and Figure S2), a three-factor model indicated that this attribute was most strongly associated with 3-MH concentration $\left(\beta_{\mathrm{w}}=0.107\right)$, with 3-MHA also positively associated $\left(\beta_{\mathrm{W}}=0.037\right)$. A further three-factor model for the data set excluding the 'reductive' AWRI1776 strain wines also indicated that 3-MH was strongly positively associated with both red fruit and cherry/confectionary aroma $\left(\beta_{\mathrm{w}}>0.1\right)$, together with hexanol and glycerol (Figure S2).

a

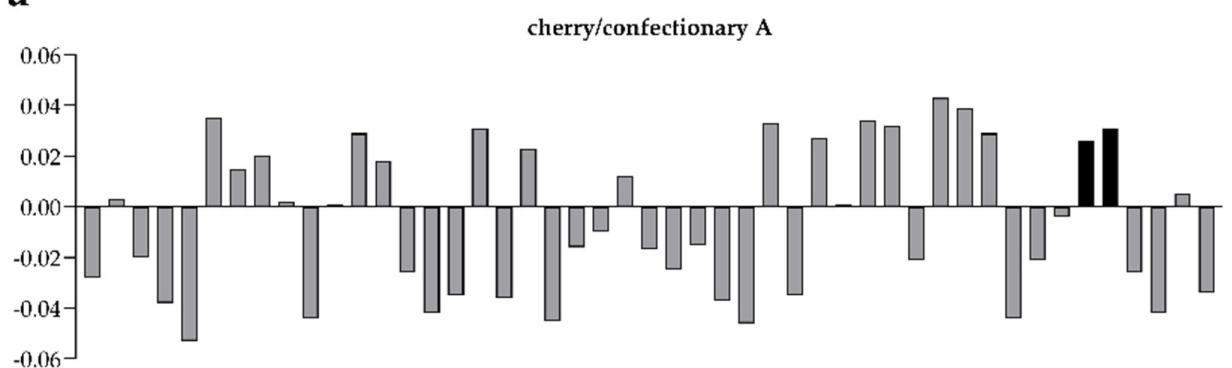

b

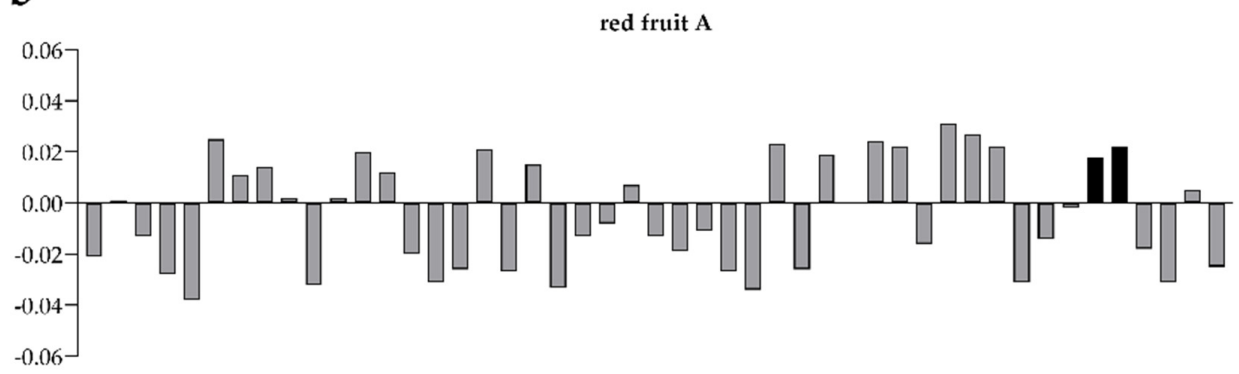

C

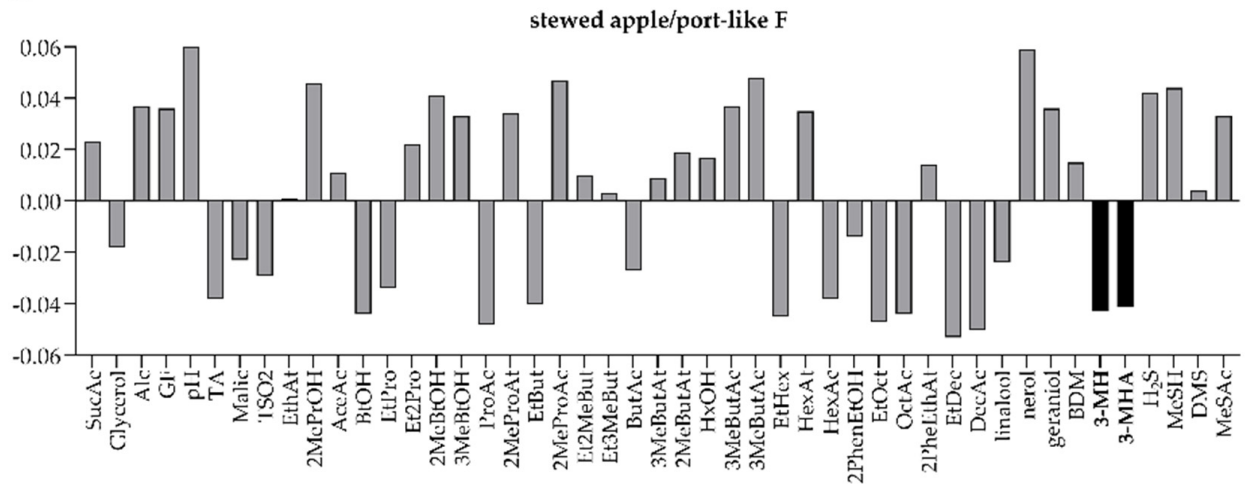

Figure 7. Regression coefficients from a partial least squares (PLS) model generated to relate volatile composition for the 6 Grenache wines made with different yeast strains with aroma (A) and flavour (F) attributes: (a) cherry/confectionary A, (b) red fruit A, (c) stewed apple/port-like F. Polyfunctional thiols 3-MH and 3-MHA are shown as black bars. Abbreviations of volatiles can be found in Table S8. 


\section{Discussion}

Previous research identified Irc7p as the primary determinant of 4-MMP release from its cysteinylated precursor Cys-4-MMP during wine fermentation [25]. Subsequent experiments in synthetic media linked a yeast-specific IRC7 genotype with the ability to release 4-MMP, and, to a lesser extent, 3-MH [16,31,43]. In the current study, we have established that yeast $\beta$-lyase activity, determined predominantly by IRC7 genotype, also plays a crucial role in modulating the release of 3-MH in Pinot Noir and Grenache wines.

Our previous attempts to reliably determine endogenous $\beta$-lyase activity of wine yeast using cell-free protein extracts, without resorting to thiol quantification by gas chromatography or by high-performance liquid chromatography-mass spectrometry, had been unsuccessful (data not shown). While both chromatographic techniques offer high sensitivity, in the $n \mathrm{~L} \mathrm{~L}^{-1}$ range, they are not always feasible as they require specialised equipment and are time-consuming $[6,25,26]$. Methods that rely on the determination of pyruvate released as a result of $\beta$-lyase activity on Cys-4-MMP or Cys-3-MH are not sufficiently sensitive to measure endogenous yeast activity, and can only be reliably used for extracts of cells overexpressing $\beta$-lyases or with the purified proteins $[16,25,42]$. The same would apply to the indirect spectrophotometric determination of free thiols using Ellman's reagent as a derivatisation agent $[25,41]$. In addition, Cys-4-MMP and Cys-3-MH are not commercially available, and their chemical synthesis in high quantities is not straightforward [33]. An alternative and commercially available cysteine $S$-conjugate, $S$-(2-Thiazolyl)-L-cysteine or STC, was used to overcome these limitations. As a result of $\beta$-lyase-catalysed cleavage on STC, 2-mercaptothiazole is released, which can be quantified using a direct spectrophotometric method in a microplate format. This method was validated in a wine yeast haploid background expressing different $I R C 7$ alleles, and the specific $\beta$-lyase activity of the $I R C 7^{L}$ allele towards STC was estimated to be sevenfold higher than that for L-cysteine, the latter being a preferred substrate over Cys-4-MMP [42].

This direct assay was then used to classify a set of 39 wine strains based on their $\beta$-lyase activity, which was found to be dependent on their $I R C 7$ genotype. Strains homozygous for the inactive allele $I R C 7^{S}$, and those with one or two copies of $I R C 7^{L}$ but harbouring inactivating SNPs, showed significantly lower $\beta$-lyase activity than strains with the fully active $I R C 7^{\mathrm{L}} / I R C 7^{L}$ genotype. From these experiments, it was estimated that $\operatorname{Irc} 7 \mathrm{p}^{\mathrm{L}}$ might account for at least $80 \%$ of the observed endogenous yeast $\beta$-lyase activity. This estimate is consistent with previous reports that showed Irc7p to be the main yeast cysteine-Sconjugate $\beta$-lyase $[16,25,43]$. The two other $\beta$-lyases identified so far, Str3p and Cys3p, are likely to have a residual contribution to thiol release under winemaking conditions [26].

Eleven S. cerevisiae strains with different genotypes and $\beta$-lyase activity levels were used to ferment a Pinot Noir must to determine whether allelic variation at the IRC7 loci affects winemaking outcomes in red varietals. The results show that variation in 3-MH concentration formed during the fermentation of this particular red must was largely explained by these factors. Strains homozygous for the fully active $I R C 7^{L}$ allele, AWRI2914 and AWRI1082, produced on average six times more 3-MH than strains homozygous for $I R C 7^{S}$. This observation supports the idea that Irc7p-dependent cleavage of Cys-3-MH was a significant contributor (approximately $80 \%$ ) to the overall production of 3-MH in the Pinot Noir wines. A similar figure was previously estimated in a synthetic media spiked with Cys-3-MH [16]. The remaining 20\% of the 3-MH found in the Pinot Noir wines might be the result of Irc7p-independent $\beta$-lyase activity, or from the condensation of $\mathrm{H}_{2} \mathrm{~S}$ (produced by the wine yeast or from elemental sulphur in the grape juice) with $\mathrm{C}_{6}$-compounds (E-2-hexenal or E-2-hexenol) found in the must [44,45]. This possible contribution of $\mathrm{H}_{2} \mathrm{~S}$ to 3-MH formation is supported by a weak but significant correlation between the concentration of 3-MH in wine and the amount of $\mathrm{H}_{2} \mathrm{~S}$ released during fermentation. 4-MMP was not detected in any of the wines, presumably due to the low concentrations of its precursors, GSH-4-MMP and Cys-4-MMP, in the must.

The concentration of 3-MH produced by the strong thiol-releasing strains was much higher than the concentrations reported in commercial Pinot Noir or rosé wines, and similar 
to those found in commercial Sauvignon Blanc wines [6]. If only the initial Cys-3-MH content in the Pinot Noir must is considered, a maximum molar conversion rate of $3.9 \%$ (or $4.3 \%$ combining both 3-MH and 3-MHA) was observed in our experimental conditions by even the strongest thiol-releasing strains. Murat, et al. [46] found a similar averaged conversion rate, $3.2 \%$, in a set of 15 Cabernet Sauvignon and Merlot rosé wines. Furthermore, if the initial concentrations of GSH-3-MH and Cys-Gly-3-MH are also considered, which are hypothesised to be converted to Cys-3-MH by multiple enzymatic activities [21,43], then the maximum conversion rate drops substantially to $0.66 \%$. These conversion rates are much lower than the percentage of precursors metabolised by yeast during fermentation. Precursor consumption was high despite the low conversion rate to free thiol, exceeding $75 \%$ for most strains. The exceptions were wines made with AWRI2865, for which there was almost no precursor loss. In a recent study in Sauvignon Blanc, a strain-dependent consumption of 3-MH precursors was also observed, as a low thiol-releasing strain showed a poor metabolising power compared with a moderate thiol releaser [47]. Once taken up by the wine yeast from the fermentation media, the fate of the different 3-MH precursors remains unknown. It has been speculated that GSH-3-MH could be converted to the tripeptide glutathione by the action of a glutathione-S-transferase activity, which is later broken down to the individual amino acids [43].

The concentrations of the three 3-MH precursors analysed were surprisingly high in the Pinot Noir juice. In particular, levels of Cys-3-MH and GSH-3-MH were slightly higher than those found in different white juices from Australia and New Zealand [18,48,49], as well as in two red cultivars (Cabernet Sauvignon and Merlot) used for rosé fermentation [46]. It has been shown that in both white and red grape cultivars, Cys-3-MH is mainly located in the grape skins [46,50], while GSH-3-MH is found both in the skins and pulp in Sauvignon Blanc [51]. Previous reports have demonstrated that prolonged pre-fermentation juice-skin contact increases the content of Cys-3-MH in both white and red musts [46,50]. Similarly, the combination of extended skin contact and high pressures during pressing also increased concentrations of Cys-3-MH in S. Blanc juice [52]. In our case, there was an extended period of skin contact ( $48 \mathrm{~h}$ ) after crushing, which could have contributed to more efficient 3-MH precursor extraction from the skins into the juice.

In the Pinot Noir ferments, no correlation was observed between $\beta$-lyase activity and $\mathrm{H}_{2} \mathrm{~S}$ concentrations (either as $\mathrm{H}_{2} \mathrm{~S}$ in the final wine or released during fermentation), despite the potential of $\operatorname{Irc} 7 \mathrm{p}^{\mathrm{L}}$ to release $\mathrm{H}_{2} \mathrm{~S}$ from L-cysteine [42]. This is not surprising, since cysteine concentration in the juice was only $1 \mathrm{mg} \mathrm{L}^{-1}$, much lower than the $K_{m}$ of Irc7 $\mathrm{p}^{\mathrm{L}}$ towards $\mathrm{H}_{2} \mathrm{~S}\left(3.8 \mathrm{mM}\right.$, about $\left.460 \mathrm{mg} \mathrm{L}^{-1}\right)$.

The compositional results obtained in the Pinot Noir laboratory-scale ferments were validated in Grenache wines made at the pilot scale (50 kg grapes) using standard red winemaking conditions. Consistent with laboratory-scale experiments, fermentation with AWRI2914 yielded wines with substantially higher 3-MH and 3-MHA concentrations compared to wines made by the other strains. The wines made with AWRI2914 were rated highly in cherry/confectionary aroma and red fruit aroma and flavour. However, AWRI1833 was also rated relatively highly in these attributes, indicating that numerous aroma compounds of multiple chemical families likely influence these sensory properties. Previous research has linked 3-MH with 'fruity' and 'citric' notes in Grenache rosé wines [53], as well as in other rosé wines from France. The PLS-R model in the present study indicated that 3-MH and 3-MHA were associated with the fruity attributes of the Grenache red wines, although for the cherry/confection aroma yeast-derived ethyl esters and their corresponding fatty acids, the monoterpene linalool and thiol DMS were also important. 3-MH and 3-MHA may act as aroma enhancers at moderate concentrations in red wine rather than acting as 'impact compounds' as categorised by Ferreira [54] in white wines.

\section{Conclusions}

Different wine yeast strains produce divergent profiles of aroma compounds, and the choice of a yeast strain can have important effects on the final flavour and aroma of wines. 
In this study, we have comprehensively demonstrated the vast range of thiol-releasing capacities across a large number of wine yeasts after fermentation of two red grape cultivars, which correlated with the presence of certain genotypes of the yeast flavour-releasing gene IRC7. Sensory analysis revealed an association of the volatile thiols 3-MH and 3-MHA with fruity aromas in Grenache wines. This knowledge will guide the choice of yeast to balance these flavour impacts and help inform strain development.

Supplementary Materials: The following supporting information can be downloaded at: https: / / www.mdpi.com/article/10.3390/pr10030502/s1. Figure S1: Correlation between 3-MH concentrations and $\mathrm{H}_{2} \mathrm{~S}$ released during fermentation of Pinot Noir must by 11 wine strains with different IRC7 genotypes. Figure S2: Regression coefficients from a partial least squares model generated to relate volatile composition for the Grenache wines made with different yeast strains with aroma attributes. Table S1: Free thiols validation. Table S2: Bound thiols validation. Table S3: Sensory attributes, definitions, and composition of reference standards for the sensory study on the Grenache wines. Table S4: Mean sensory attribute scores for the yeast strains and Tukey's honestly significant different test values. Table S5: Cysteine-S-conjugate $\beta$-lyase activity towards STC in cell-free protein extracts from 39 yeast strains with different IRC7 genotypes. Table S6: Pearson correlation coefficients between the concentrations of free thiols and their precursors in Pinot Noir wines fermented with 11 strains with different $I R C 7$ genotypes. Table S7: Pearson correlation coefficients for the concentrations of free thiols and volatile sulphur compounds in Pinot Noir wines fermented with 11 strains with different $I R C 7$ genotypes. Table S8: Summary of volatile and non-volatile compounds produced by six wine yeast strains in Grenache wine after 9 months in bottle. Table S9: Probability values, degrees of freedom, and mean square error from the analysis of variance.

Author Contributions: Conceptualization, A.G.C., S.A.S. and C.D.C.; methodology, A.G.C., D.E.N., M.S., A.C.K., F.W., L.P. and C.D.C.; validation, M.S., A.C.K., F.W. and L.P., formal analysis, D.E.N., M.S., A.C.K., F.W. and L.P.; investigation, A.G.C.; writing-original draft preparation, A.G.C.; writing - review and editing, A.G.C., D.E.N., S.A.S. and C.D.C.; visualization, A.G.C., D.E.N. and S.A.S. All authors have read and agreed to the published version of the manuscript.

Funding: The Australian Wine Research Institute (AWRI), a member of the Wine Innovation Cluster in Adelaide, is supported by Australia's grapegrowers and winemakers through their investment body Wine Australia, with matching funds from the Australian Government.

Institutional Review Board Statement: Not applicable.

Informed Consent Statement: Not applicable.

Data Availability Statement: All data has been made available through the manuscript itself or via Supplementary Materials.

Acknowledgments: The Australian Wine Research Institute (AWRI), a member of the Wine Innovation Cluster in Adelaide, is supported by Australia's grapegrowers and winemakers through their investment body Wine Australia, with matching funds from the Australian Government. Special thanks to Leigh Francis for editing and advice. The authors also would like to thank the members of the AWRI's descriptive analysis sensory panel as well as colleagues Eleanor Bilogrevic and Desireé Likos for their involvement in the sensory evaluations. The authors also thank John Gledhill for his valuable contribution to the winemaking.

Conflicts of Interest: The authors declare no conflict of interest. The funders had no role in the design of the study; in the collection, analyses, or interpretation of data; in the writing of the manuscript, or in the decision to publish the results.

Sample Availability: Samples are available from the authors for a limited time. Wine will not be stored indefinitely.

\section{References}

1. Darriet, P.; Tominaga, T.; Lavigne, V.; Boidron, J.-N.; Dubourdieu, D. Identification of a powerful aromatic component of Vitis vinifera L. var. sauvignon wines: 4-mercapto-4-methylpentan-2-one. Flavour Fragr. J. 1995, 10, 385-392. [CrossRef]

2. Tominaga, T.; Furrer, A.; Henry, R.; Dubourdieu, D. Identification of new volatile thiols in the aroma of Vitis vinifera L. var. Sauvignon blanc wines. Flavour Fragr. J. 1998, 13, 159-162. [CrossRef] 
3. Tominaga, T.; Darriet, P.; Dubourdieu, D. Identification de l'acétate de 3-mercaptohexanol, composé à forte odeur de buis, intervenant dans l'arôme des vins de Sauvignon. Vitis 1996, 35, 207-210.

4. Capone, D.L.; Barker, A.; Williamson, P.O.; Francis, I.L. The role of potent thiols in Chardonnay wine aroma. Aust. J. Grape Wine Res. 2017, 24, 38-50. [CrossRef]

5. Guth, H. Quantitation and sensory studies of character impact odorants of different white wine varieties. J. Agric. Food Chem. 1997, 45, 3027-3032. [CrossRef]

6. Capone, D.L.; Ristic, R.; Pardon, K.H.; Jeffery, D.W. Simple quantitative determination of potent thiols at ultratrace levels in wine by derivatization and high-performance liquid chromatography-tandem mass spectrometry (HPLC-MS/MS) analysis. Anal. Chem. 2015, 87, 1226-1231. [CrossRef] [PubMed]

7. Rigou, P.; Triay, A.; Razungles, A. Influence of volatile thiols in the development of blackcurrant aroma in red wine. Food Chem. 2014, 142, 242-248. [CrossRef]

8. Culleré, L.; Escudero, A.; Cacho, J.; Ferreira, V. Gas chromatography-olfactometry and chemical quantitative study of the aroma of six premium quality spanish aged red wines. J. Agric. Food Chem. 2004, 52, 1653-1660. [CrossRef] [PubMed]

9. Siebert, T.E.; Francis, I.L.; Pisaniello, L.; Melzer, S.; Bey, L.; Watson, F.; Cordente, T. Do varietal thiols matter in red wine? AWRI Technol. Rev. 2019, 183, 10-15.

10. Fang, Y.; Qian, M. Aroma compounds in Oregon Pinot Noir wine determined by aroma extract dilution analysis (AEDA). Flavour Fragr. J. 2005, 20, 22-29. [CrossRef]

11. Smith, M.E.; Bekker, M.Z.; Smith, P.A.; Wilkes, E.N. Sources of volatile sulfur compounds in wine. Aust. J. Grape Wine Res. 2015, 21,705-712. [CrossRef]

12. Swiegers, J.H.; Pretorius, I.S. Modulation of volatile sulfur compounds by wine yeast. Appl. Microbiol. Biotechnol. 2007, 74, 954-960. [CrossRef] [PubMed]

13. Howell, K.; Swiegers, J.H.; Elsey, G.M.; Siebert, T.E.; Bartowsky, E.J.; Fleet, G.H.; Pretorius, I.S.; de Barros Lopes, M.A. Variation in 4-mercapto-4-methyl-pentan-2-one release by Saccharomyces cerevisiae commercial wine strains. FEMS Microbiol. Lett. 2004, 240, 125-129. [CrossRef] [PubMed]

14. King, E.S.; Swiegers, J.H.; Travis, B.; Francis, I.L.; Bastian, S.E.; Pretorius, I.S. Coinoculated Fermentations Using Saccharomyces Yeasts Affect the Volatile Composition and Sensory Properties of Vitis vinifera L. cv. Sauvignon Blanc Wines. J. Agric. Food Chem. 2008, 56, 10829-10837. [CrossRef] [PubMed]

15. Murat, M.-L.; Masneuf, I.; Darriet, P.; Lavigne, V.; Tominaga, T.; Dubourdieu, D. Effect of Saccharomyces cerevisiae Yeast Strains on the Liberation of Volatile Thiols in Sauvignon blanc Wine. Am. J. Enol. Vitic. 2001, 52, 136.

16. Cordente, A.G.; Borneman, A.R.; Bartel, C.; Capone, D.; Solomon, M.; Roach, M.; Curtin, C.D. Inactivating Mutations in Irc7p Are Common in Wine Yeasts, Attenuating Carbon-Sulfur $\beta$-Lyase Activity and Volatile Sulfur Compound Production. Appl. Environ. Microbiol. 2019, 85, e02684-18. [CrossRef]

17. Tofalo, R.; Perpetuini, G.; Battistelli, N.; Tittarelli, F.; Suzzi, G. Correlation between IRC7 gene expression and 4-mercapto-4methylpentan-2-one production in Saccharomyces cerevisiae strains. Yeast 2020, 37, 487-495. [CrossRef]

18. Capone, D.L.; Sefton, M.A.; Hayasaka, Y.; Jeffery, D.W. Analysis of precursors to wine odorant 3-mercaptohexan-1-ol using HPLC-MS/MS: Resolution and quantitation of diastereomers of 3-S-cysteinylhexan-1-ol and 3-S-glutathionylhexan-1-ol. J. Agric. Food Chem. 2010, 58, 1390-1395. [CrossRef]

19. Fedrizzi, B.; Pardon, K.H.; Sefton, M.A.; Elsey, G.M.; Jeffery, D.W. First identification of 4-S-glutathionyl-4-methylpentan-2-one, a potential precursor of 4-mercapto-4-methylpentan-2-one, in Sauvignon Blanc juice. J. Agric. Food Chem. 2009, 57, 991-995. [CrossRef]

20. Capone, D.L.; Pardon, K.H.; Cordente, A.G.; Jeffery, D.W. Identification and quantitation of 3-S-cysteinylglycinehexan-1-ol (Cysgly-3-MH) in Sauvignon blanc grape juice by HPLC-MS/MS. J. Agric. Food Chem. 2011, 59, 11204-11210. [CrossRef]

21. Cordente, A.G.; Capone, D.L.; Curtin, C.D. Unravelling glutathione conjugate catabolism in Saccharomyces cerevisiae: The role of glutathione/dipeptide transporters and vacuolar function in the release of volatile sulfur compounds 3-mercaptohexan-1-ol and 4-mercapto-4-methylpentan-2-one. Appl. Microbiol. Biotechnol. 2015, 99, 9709-9722. [CrossRef] [PubMed]

22. Bonnaffoux, H.; Roland, A.; Remond, E.; Delpech, S.; Schneider, R.; Cavelier, F. First identification and quantification of S-3(hexan-1-ol)-gamma-glutamyl-cysteine in grape must as a potential thiol precursor, using UPLC-MS/MS analysis and stable isotope dilution assay. Food Chem. 2017, 237, 877-886. [CrossRef] [PubMed]

23. Swiegers, J.H.; Willmott, R.; Hill-Ling, A.; Capone, D.L.; Pardon, K.H.; Elsey, G.M.; Howell, K.S.; de Barros Lopes, M.A.; Sefton, M.A.; Lilly, M.; et al. Modulation of volatile thiol and ester aromas by modified wine yeast. In Developments in Food Science; Bredie, W.L.P., Petersen, M.A., Eds.; Elsevier: Amsterdam, The Netherlands, 2006; Volume 43, pp. 113-116.

24. Lilly, M.; Lambrechts, M.G.; Pretorius, I.S. Effect of increased yeast alcohol acetyltransferase activity on flavor profiles of wine and distillates. Appl. Environ. Microbiol. 2000, 66, 744-753. [CrossRef]

25. Roncoroni, M.; Santiago, M.; Hooks, D.O.; Moroney, S.; Harsch, M.J.; Lee, S.A.; Richards, K.D.; Nicolau, L.; Gardner, R.C. The yeast IRC7 gene encodes a beta-lyase responsible for production of the varietal thiol 4-mercapto-4-methylpentan-2-one in wine. Food Microbiol. 2011, 28, 926-935. [CrossRef] [PubMed]

26. Holt, S.; Cordente, A.G.; Williams, S.J.; Capone, D.L.; Jitjaroen, W.; Menz, I.R.; Curtin, C.; Anderson, P.A. Engineering Saccharomyces cerevisiae to release 3-mercaptohexan-1-ol during fermentation through overexpression of an S. cerevisiae gene, STR3, for improvement of wine aroma. Appl. Environ. Microbiol. 2011, 77, 3626-3632. [CrossRef] 
27. Zha, M.; Yin, S.; Sun, B.; Wang, X.; Wang, C. STR3 and CYS3 Contribute to 2-Furfurylthiol Biosynthesis in Chinese Sesame-Flavored Baijiu Yeast. J. Agric. Food Chem. 2017, 65, 5503-5511. [CrossRef]

28. Howell, K.; Klein, M.; Swiegers, J.H.; Hayasaka, Y.; Elsey, G.M.; Fleet, G.H.; de Barros Lopes, M.A.; Høj, P.B.; Pretorius, I.S. Genetic determinants of volatile-thiol release by Saccharomyces cerevisiae during wine fermentation. Appl. Environ. Microbiol. 2005, 71, 5420-5426. [CrossRef]

29. Belda, I.; Ruiz, J.; Navascues, E.; Marquina, D.; Santos, A. Improvement of aromatic thiol release through the selection of yeasts with increased beta-lyase activity. Int. J. Food Microbiol. 2016, 225, 1-8. [CrossRef]

30. Ruiz, J.; de Celis, M.; Martín-Santamaría, M.; Benito-Vázquez, I.; Pontes, A.; Lanza, V.F.; Sampaio, J.P.; Santos, A.; Belda, I. Global distribution of IRC7 alleles in Saccharomyces cerevisiae populations: A genomic and phenotypic survey within the wine clade. Environ. Microbiol. 2021, 23, 3182-3195. [CrossRef]

31. Dufour, M.; Zimmer, A.; Thibon, C.; Marullo, P. Enhancement of volatile thiol release of Saccharomyces cerevisiae strains using molecular breeding. Appl. Microbiol. Biotechnol. 2013, 97, 5893-5905. [CrossRef]

32. Kotseridis, Y.; Ray, J.-L.; Augier, C.; Baumes, R. Quantitative determination of sulfur containing wine odorants at sub-ppb levels. 1. Synthesis of the deuterated analogues. J. Agric. Food Chem. 2000, 48, 5819-5823. [CrossRef] [PubMed]

33. Pardon, K.H.; Graney, S.D.; Capone, D.L.; Swiegers, J.H.; Sefton, M.A.; Elsey, G.M. Synthesis of the individual diastereomers of the cysteine conjugate of 3-mercaptohexanol (3-MH). J. Agric. Food Chem. 2008, 56, 3758-3763. [CrossRef] [PubMed]

34. Grant-Preece, P.A.; Pardon, K.H.; Capone, D.L.; Cordente, A.G.; Sefton, M.A.; Jeffery, D.W.; Elsey, G.M. Synthesis of wine thiol conjugates and labeled analogues: Fermentation of the glutathione conjugate of 3-mercaptohexan-1-ol yields the corresponding cysteine conjugate and free thiol. J. Agric. Food Chem. 2010, 58, 1383-1389. [CrossRef] [PubMed]

35. Cordente, A.G.; Heinrich, A.; Pretorius, I.S.; Swiegers, J.H. Isolation of sulfite reductase variants of a commercial wine yeast with significantly reduced hydrogen sulfide production. FEMS Yeast Res. 2009, 9, 446-459. [CrossRef]

36. Siebert, T.E.; Solomon, M.R.; Pollnitz, A.P.; Jeffery, D.W. Selective determination of volatile sulfur compounds in wine by gas chromatography with sulfur chemiluminescence detection. J. Agric. Food Chem. 2010, 58, 9454-9462. [CrossRef]

37. Winter, G.; Henschke, P.A.; Higgins, V.J.; Ugliano, M.; Curtin, C.D. Effects of rehydration nutrients on H2S metabolism and formation of volatile sulfur compounds by the wine yeast VL3. AMB Express 2011, 1, 36. [CrossRef]

38. Cordente, A.G.; Espinase Nandorfy, D.; Solomon, M.; Schulkin, A.; Kolouchova, R.; Francis, I.L.; Schmidt, S.A. Aromatic Higher Alcohols in Wine: Implication on Aroma and Palate Attributes during Chardonnay Aging. Molecules 2021, 26, 4979. [CrossRef]

39. Heymann, H.; King, E.; Hopfer, H. Classical Descriptive Analysis. In Novel Techniques in Sensory Characterization and Consumer Profiling, 1st ed.; Varela, P., Ares, G., Eds.; CRC Press: Boca Raton, FL, USA, 2014; pp. 9-40.

40. Day, M.; Espinase Nandorfy, D.; Bekker, M.; Bindon, K.; Solomon, M.; Smith, P.; Schmidt, S. Aeration of Vitis vinifera Shiraz fermentation and its effect on wine chemical composition and sensory attributes. Aust. J. Grape Wine Res. 2021, 27, 360-377. [CrossRef]

41. Swiegers, J.H.; Capone, D.L.; Pardon, K.H.; Elsey, G.M.; Sefton, M.A.; Francis, I.L.; Pretorius, I.S. Engineering volatile thiol release in Saccharomyces cerevisiae for improved wine aroma. Yeast 2007, 24, 561-574. [CrossRef]

42. Santiago, M.; Gardner, R.C. TheIRC7gene encodes cysteine desulphydrase activity and confers on yeast the ability to grow on cysteine as a nitrogen source. Yeast 2015, 32, 519-532. [CrossRef]

43. Santiago, M.; Gardner, R.C. Yeast genes required for conversion of grape precursors to varietal thiols in wine. FEMS Yeast Res. 2015, 15, fov034. [CrossRef] [PubMed]

44. Araujo, L.D.; Vannevel, S.; Buica, A.; Callerot, S.; Fedrizzi, B.; Kilmartin, P.; du Toit, W.J. Indications of the prominent role of elemental sulfur in the formation of the varietal thiol 3-mercaptohexanol in Sauvignon blanc wine. Food Res. Int. 2017, 98, 79-86. [CrossRef] [PubMed]

45. Harsch, M.J.; Benkwitz, F.; Frost, A.; Colonna-Ceccaldi, B.; Gardner, R.C.; Salmon, J.-M. New precursor of 3-mercaptohexan-1-ol in grape juice: Thiol-forming potential and kinetics during early stages of must fermentation. J. Agric. Food Chem. 2013, 61, 3703-3713. [CrossRef] [PubMed]

46. Murat, M.-L.; Tominaga, T.; Dubourdieu, D. Assessing the Aromatic Potential of Cabernet Sauvignon and Merlot Musts Used to Produce Rose Wine by Assaying the Cysteinylated Precursor of 3-Mercaptohexan-1-ol. J. Agric. Food Chem. 2001, 49, 5412-5417. [CrossRef] [PubMed]

47. Wang, X.; Chen, L.; Capone, D.L.; Roland, A.; Jeffery, D.W. Evolution and Correlation of cis-2-Methyl-4-propyl-1,3-oxathiane, Varietal Thiols, and Acetaldehyde during Fermentation of Sauvignon blanc Juice. J. Agric. Food Chem. 2020, 68, $8676-8687$. [CrossRef] [PubMed]

48. Capone, D.L.; Sefton, M.A.; Jeffery, D.W. Application of a modified method for 3-mercaptohexan-1-ol determination to investigate the relationship between free thiol and related conjugates in grape juice and wine. J. Agric. Food Chem. 2011, 59, 4649-4658. [CrossRef]

49. Pinu, F.R.; Jouanneau, S.; Nicolau, L.; Gardner, R.C.; Villas-Boas, S.G. Concentrations of the Volatile Thiol 3-Mercaptohexanol in Sauvignon blanc Wines: No Correlation with Juice Precursors. Am. J. Enol. Vitic. 2012, 63, 407-412. [CrossRef]

50. Peyrot des Gachons, C.; Tominaga, T.; Dubourdieu, D. Localization of S-cysteine conjugates in the berry: Effect of skin contact on aromatic potential of Vitis vinifera L. cv. Sauvignon Blanc must. Am. J. Enol. Vitic. 2002, 53, 144.

51. Roland, A.; Schneider, R.; Charrier, F.; Cavelier, F.; Rossignol, M.; Razungles, A. Distribution of varietal thiol precursors in the skin and the pulp of Melon B. and Sauvignon Blanc grapes. Food Chem. 2011, 125, 139-144. [CrossRef] 
52. Maggu, M.; Winz, R.; Kilmartin, P.A.; Trought, M.C.T.; Nicolau, L. Effect of Skin Contact and Pressure on the Composition of Sauvignon Blanc Must. J. Agric. Food Chem. 2007, 55, 10281-10288. [CrossRef]

53. Ferreira, V.; Ortín, N.; Escudero, A.; López, R.; Cacho, J. Chemical Characterization of the Aroma of Grenache Rosé Wines: Aroma Extract Dilution Analysis, Quantitative Determination, and Sensory Reconstitution Studies. J. Agric. Food Chem. 2002, 50, 4048-4054. [CrossRef] [PubMed]

54. Ferreira, V. Volatile aroma compounds and wine sensory attributes. In Managing Wine Quality; Reynolds, A.G., Ed.; Woodhead Publishing: New York, NY, USA, 2010; pp. 3-28. 